\title{
MicroRNAs from plants to animals, do they define a new messenger for communication?
}

\author{
Zhiqing $\mathrm{Li}^{1}$, Ruodan $\mathrm{Xu}^{2,3}$ and Ning $\mathrm{Li}^{2^{*}}$ (D)
}

\begin{abstract}
MicroRNAs (miRNAs), a class of single-stranded non-coding RNA of about 22 nucleotides, are potent regulators of gene expression existing in both plants and animals. Recent studies showed that plant miRNAs could enter mammalian bloodstream via gastrointestinal tract, through which access a variety of tissues and cells of recipients to exert therapeutic effects. This intriguing phenomenon indicates that miRNAs of diet/plant origin may act as a new class of bioactive ingredients communicating with mammalian systems. In this review, in order to pinpoint the reason underlying discrepancies of miRNAs transmission from diet/plant to animals, the pathways that generate miRNAs and machineries involved in the functions of miRNAs in both kingdoms were outlined and compared. Then, the current controversies concerning cross-kingdom regulations and the potential mechanisms responsible for absorption and transfer of diet/plant-derived miRNAs were interpreted. Furthermore, the hormone-like action of miRNAs and the intricate interplay between miRNAs and hormones were implicated. Finally, how these findings may impact nutrition and medicine were briefly discussed.
\end{abstract}

Keywords: MicroRNAs (miRNAs), Small RNAs (sRNAs), Cross-kingdom communication, Gene regulation, Oral delivery, Herbal medicines, Hormones

\section{Background}

MicroRNAs (miRNAs) are an extensive class of single-stranded non-coding RNA, 19-24 nucleotides in length, which negatively regulate gene expression at post-transcriptional level. Initiated by the discovery of lin-4 in Caenorhabditis elegans (C. elegans) [1-3], thousands of miRNAs have been identified in plants, animals and other eukaryotes [4]. So far, over 38,589 miRNA gene loci distributed over 271 species have been stored in the latest miRBase (Release 22, March 2018, http://www.mirbase.org/). Through complementary base pairing, miRNAs can effectively inhibit translation or mediate degradation of target mRNAs (messenger RNAs). Both pleiotropically and ubiquitously, a single miRNA is often capable of recognizing hundreds of distinct mRNA transcripts. Likewise, one mRNA molecule usually has multiple miRNA binding sites and miRNAs binding to a single mRNA often act in

\footnotetext{
*Correspondence: lili.li.ning@gmail.com

${ }^{2}$ Institute of Basic Theory for Chinese Medicine, China Academy of Chinese

Medical Sciences, Beijing 100700, People's Republic of China

Full list of author information is available at the end of the article
}

a synergistic fashion [5]. MiRNAs play crucial roles in a wide range of biological processes, including developmental timing [6-8], cell differentiation [9-11], proliferation $[12,13]$, apoptosis [14-17] and metabolism [18], as such participate in a variety of human diseases [19-21]. It is estimated that $60 \%$ of all mammalian protein-coding genes are regulated by at least one miRNA [22, 23].

Our daily diet provides not only essential nutrients required for survival and growth but also bioactive compounds for health promotion and disease prevention [24]. Epidemiology studies have consistently shown that regular consumption of plant-based foods, such as fruit, vegetables and whole grains is beneficial for metabolic disease, cancer and age-related functional decline $[25,26]$. However, the mechanistic understanding of the demonstrated impacts of plant-rich diets is still on their way to be clarified. It is generally believed that the bioactive components consumed from plants, such as flavonoids, phenolic acids and carotenoids contribute to lower risks of major chronic diseases [27]. Nonetheless, there is an intriguing phenomenon that synthetic supplements of phytochemicals are often not as 
efficient as complex plant materials, like vitamins, possibly implying the diversity of bioactive substances in plants and the existence of certain unidentified bioactive components.

In 2012, Zhang et al. [28] reported that diet/plant-derived miRNAs could be detected in the serum of human or plant-feeding animals, thus further regulate gene expression of recipients in a sequence-specific manner. Later on, Zhou [29] demonstrated that honeysuckle-encoded miRNA, miR2911, could be taken up via gastrointestinal (GI) tract of Influenza A virus (IAV)-infected mice and counteract viral infections. These findings constitute the initial clues that miRNAs may act as new bioactive constituents of plants and have the potential travelling from plants to animals via GI tract to access their cellular targets, influencing the physio-pathological conditions of their recipients. If the above described miRNAs transmission from plants to human (the so called cross-kingdom transmission) is validated, it may revolutionize our current knowledge of the properties, effectiveness and biological actions of bioactive compounds in diets [30,31].

This review aims to summarize and analyze the main supporting and contradicting evidence of cross-kingdom regulation of miRNAs for a better comprehension of their potentials as a new effective constituent in plant-based diet and medication. To commence, the similarities and imparities of miRNAs between plants and animals are overviewed. For both kingdoms, the biogenesis of miRNAs, recognition of their targets and their mode of actions are particularly summarized and compared. Then, current evidence concerning cross-kingdom regulations of plant-derived miRNAs is outlined and the putative mechanisms of action responsible for efficient transfer from plant-derived sources to human cells are proposed. Furthermore, the hormone-like action of miRNAs and the intricate interplay between miRNAs and hormones are implicated. Finally, the potential impact of these findings on the progress of the study of nutrition and medicine is briefly discussed.

\section{Biogenesis of miRNAs}

Both in plants and animals, biogenesis of miRNAs initiates within the nucleus. Most miRNAs are transcribed by polymerase (Pol) II [32, 33], while a subset of animal miRNAs are products of RNA Pol III [34] (Fig. 1). The initial miRNA transcript is called primary miRNA (pri-miRNA), which contains a stable stem-loop structure. The pri-miRNA consists of thousands of nucleotides [35] and begins with a 7-methylguanosine $\left(\mathrm{m}^{7} \mathrm{G}\right)$ cap and ends with a $3^{\prime}$ poly(A) tail both in plants and animals. While, differences exist in the subsequent generating process of functionally mature miRNAs.

In animals, a long pri-miRNA is first cleaved by a ribonuclease (RNase) III, called Drosha, together with its double-stranded RNA (dsRNA)-binding protein partner DGCR8 (DiGeorge syndrome critical region gene 8 , in mammals) or Pasha (in flies) [36-39], releasing a 70-nt hairpin precursor miRNA (pre-miRNA) within the nucleus. Afterwards, recognized by another RNase III Exportin-5, the pre-miRNA can be transported into the cytoplasm in a Ran (ras-related nuclear protein)-GTP (guanosine triphosphate)-dependent manner [40, 41]. Subsequently, another RNase III enzyme, Dicer, along with its dsRNA-binding partner transactivation-response RNA-binding protein (TRBP, in mammals) or Loquacious (Loqs, in flies) liberates pre-miRNA stem loop to generate a miRNA/miRNA* duplex [42-46]. In the cytoplasm, the miRNA/miRNA* duplex is separated; the miRNA strand is incorporated into RISC (RNA-induced silencing complex), whereas the miRNA* strand is typically degraded by an unknown mechanism. For slicing to occur, Argonaute (Ago), a core component of the RISC must be contained. Among the four mammalian Ago proteins, only Ago 2 possesses "slicer" capabilities [47]. In cases in which cleavage is not possible, Ago proteins recruit additional protein partners to mediate silencing [48].

While in plants, due to the lack of Drosha genes, the cleavage of pri-miRNAs is carried out by the plant RNase-III-like protein. Among the four Dicer-like enzymes in plants, Dicer-like (DCL) 1 is responsible for the bulk of biogenesis of miRNAs [49]. DCL1 mainly processes the pri-miRNA in two steps. It firstly cuts off the imperfectly folded end of the pri-miRNA to generate the pre-miRNA with a stem-loop hairpin secondary structure. The resulting pre-miRNA is further excised by DCL1 to produce a miRNA/miRNA* duplex [50]. Unlike animals, biogenesis of miRNA/miRNA* in plant is completed within the nucleus [51] in a nuclear processing center termed dicing bodies (D-bodies) [52, 53]. Another remarkable difference lies in that plant miRNAs are universally methylated at their $3^{\prime}$ ends while most products of animal miRNA genes are not. Following the releasing of the initial miRNA/miRNA* duplexes, they are then $3^{\prime}$-terminal 2'-O-methylated by a small RNA methyl transferase, called Hua Enhancer (HEN)1. This modification prevents their uridylation and subsequent degradation [54]. Methylated miRNA/ miRNA* duplexes are then exported from nucleus into cytoplasm for loading into cytoplasmic Ago proteins via a pathway controlled by the Hasty (HST), a plant homologue of Exportin-5 [51]. In comparison of animal miRNAs, ten Ago family members are present in plants, among which the predominant effector for miRNA-mediated reactions of silencing is Ago1 [55, 56] and most other plant Ago proteins are also likely to possess RNA cleavage activities [57]. 


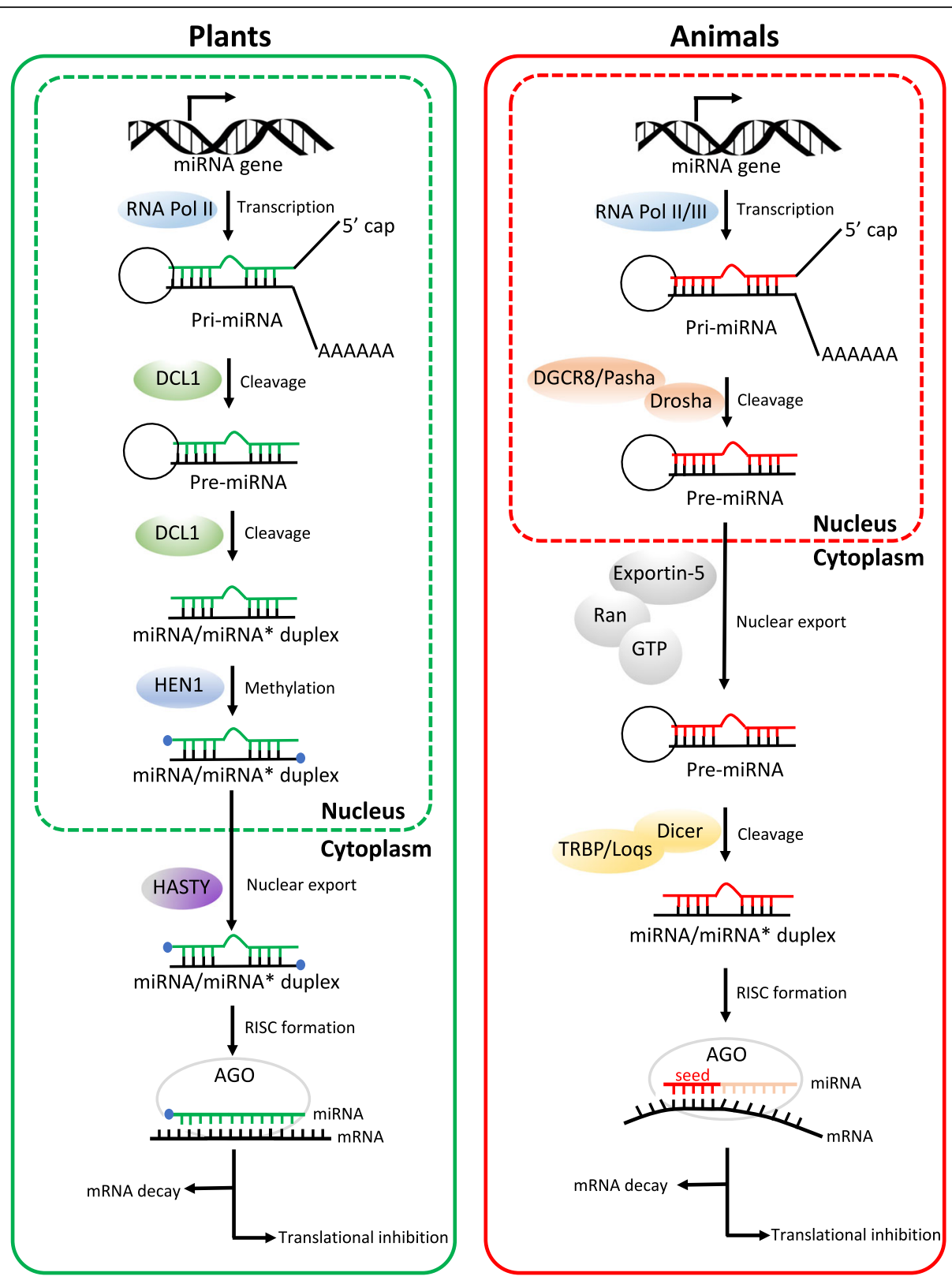

Fig. 1 Comparison of miRNA biogenesis and activity pathways in plants and animals. Both in plants and animals, biogenesis of miRNAs initiates within the nucleus. In plants, miRNA/miRNA* duplexes are cleaved from pri-miRNAs through the action of DCL1 endonuclease in two steps. DCL1 firstly cuts off the imperfectly folded ends of pri-miRNAs to generate pre-miRNAs with stem-loop hairpin secondary structures. The resulting premiRNAs are further excised by DCL1 to mature miRNA/miRNA* duplexes. Then the 3 '-terminal of duplexes is methylated by HEN1. By contrast, in animals, pre-miRNAs are produced in the nucleus by the action of the Drosha enzyme, together with its DGCR8 protein (in mammals) or Pasha protein (in flies). Duplexes of miRNA/miRNA* are further processed after exporting from nucleus to cytoplasm, where pre-miRNAs are cleaved by Dicer and TRBP (in mammals) or Logs (in flies). In plants, HASTY is responsible for the transport of miRNA/miRNA* duplexes from nucleus to cytoplasm, whereas in animals, pre-miRNAs are recognized and then exported by Exportin-5 in a Ran-GTP-dependent manner. During RISC loading, one strand of the small RNA duplexes is selected as the guide strand (green in plants or red in animals) and incorporated into Ago to form a functional RISC, whereas the other strand is removed and degraded. In plants, miRNAs have near-perfect complementarity to their target mRNAs. By contrast, animal miRNAs often have targets with imperfect complementarity and the major determinant for animal miRNAs binding to their target mRNAs is a 6-8 nucleotide domain at the 5' extremity or seed sequence. Arrows indicate the direction of the subsequent activity pathways. Both plant and animal miRNAs can regulate gene expression via mRNA decay and translational inhibition 


\section{Target recognition of miRNAs}

Identification of miRNA targets is the key for understanding miRNA function. The imperfect complementarity nature of base pairing between miRNAs and their mRNA targets in animals makes it challenging to systematically identify mRNA targets [22]. Functional recognition of miRNA target is known to principally comply with the seed rule, which defines that contiguous base pairing to the $5^{\prime}$ end of miRNAs, especially nucleotides $2-7$, is crucial for targeting [58]. Such seed sites initially came from the first discovered miRNA lin-4, which had some sequence complementarity to multiple conserved sites within the lin-14 RNA [1]. Hereafter, seed rule was further confirmed by large-scale studies monitoring whole transcriptome and proteome responses to miRNAs [59-63]. Practically, when applied in combination with evolutionary conservation [58], secondary structure [64] or neighboring context information [60] of mRNA, the seed rule is informatively valuable in prediction and analysis of canonical seed sites. However, there remain a certain number of target sites failed to be identified based on the perfect seed complementarity [65-68]. In fact, several biological studies have validated that perfectly matched miRNA seeds are neither necessary nor sufficient for detecting all functional miRNA-target interactions [69, 70]. Recent advances in a transcriptome-wide method of precisely mapping miRNA binding sites (Ago HITS-CLIP (High-throughput sequencing together with UV-crosslinking and immunoprecipitation) method) unexpectedly revealed that a large percentage of miRNA-mRNA interactions were not merely mediated by seed sites, but mediation by non-canonical sites required consideration $[71,72]$. By far, the add-on modes of target recognition include pivot seed pairing or nucleation bulge [73], centering pairing miRNA-binding sites [74] and seed-like motifs [75-77].

In contrast to animal miRNAs, target recognition of plant miRNAs was primarily believed simple and straightforward, as most plant miRNAs had perfect or near-perfect complementarity to their target mRNAs. However, Brodersen et al. showed that translational repression was a widespread mechanism fulfilled by plant miRNAs [78], highlighting the enormous diversity and complexity of gene regulation in plant systems. Recent studies were more likely to reach a consensus on the 'rules' of base-pairing for a functional plant miRNA-target interaction: little tolerance of mismatches at positions 213 , especially positions $9-11$, and more tolerance of mismatches at 1 and 14-21 [79]. Although high complementarity between plant miRNA and their target was a prerequisite for silencing efficacy, deviations from this rule were also observed. One example was Arabidopsis miR398a, which post-transcriptionally regulated its target gene copper/zinc superoxide dismutase (CSD)2, despite the presence of a bulge and GU wobble in the crucial 213 region [80]. Similarly, another Arabidopsis miR398-blue copper-binding protein interaction had a 6-nt bulge between positions 6 and 7 of the miRNA [81]. Such studies indicated that complementarity might not be the sole determinant for efficient silencing; additional features, such as the accessibility or secondary structure of target mRNA [82], the RNA-binding proteins [83] and the stoichiometric ratio between miRNA and target mRNA abundance [84] should be taken into account.

With regard to target site positions in mRNAs, animal miRNAs were once thought to bind target mRNAs mainly on the $3^{\prime}$ untranslated region (UTR), while plant mRNAs that were regulated by miRNAs predominately located in the coding sequences (CDS). More insightful studies have provided evidence that both animal and plant miRNAs can target 5' UTR, 3' UTR and CDS [85, 86], suggesting the diversity of miRNAs binding sites and similarities in both kingdoms.

Successful target recognition of miRNAs relies additionally on their stabilities modulated by target transcripts. Previous studies have provided interesting evidence of reciprocal regulations between miRNAs and their target sequences, such that target RNAs can in turn modulate miRNA decay [8789]. The extent of sequence complementarity appears to be crucial for miRNA degradation both in plants and animals [90]. In animals, as complementarity of miRNAs is limited to the seed for most endogenous targets and the unmethylated miRNA 3' end may be leaved inside the Ago, miRNA degradation by target transcripts is uncommon [87]. However, exposure of a miRNA to an artificial target RNA with extensive pairing leads to miRNA 3 ' trimming and tailing, perhaps via dislodging the miRNA 3' end from Ago [87-89]. Compared with miRNAs in animals, plant miRNAs are nearly perfectly complementary to their target RNAs and extensive pairing may expose 3' end of miRNAs [90]. When in the absence of methyltransferase activity of HEN1, an unmethylated miRNA is subject to $3^{\prime}$ trimming and tailing by enzymes [91]. Although the 2'-O-methylation on the $3^{\prime}$ terminal ribose markedly stabilizes plant miRNAs, methylated miRNAs can be degraded as well, which is possibly associated with demethylation [90]. Beyond target-dependent mechanisms, other factors impacting miRNA stability involve miRNA-degrading enzymes [92], cis-elements in miRNAs [93] and RNA-binding proteins [94]. To date, the dynamics of miRNA degradation and the associated molecular mechanisms remain largely obscure. Further effort will be needed to clarify how plant miRNAs are subject to degradation in animal kingdom system.

\section{Mechanism of miRNAs' action}

In both plants and animals, miRNAs need to form a ribonucleoprotein complex, RISC, to silence target 
mRNAs [95, 96]. The minimal RISC consists of a small RNA (sRNA) and Ago [97]. The miRNAs exert gene silencing through two main mechanisms: mRNA decay and translational repression [96]. The mode of target repression has been largely determined by the degree of complementarity between the miRNA and its mRNA targets. High complementarity, as seen in plants, promotes target cleavage by RISC, while seed-matching often leads to translational inhibition, which is believed the dominant mode of miRNAs' action in animals [98]. In recent years, the boundaries between plant and animal miRNAs in terms of mechanisms of action are becoming blurry as there is more evidence showing that miRNA decay and translational inhibition can occur in both kingdoms. Even though, they may operate by mechanisms of fine distinctions.

\section{miRNA-mediated mRNA decay in animals}

Animal miRNAs were initially thought not to affect target mRNA levels, but only to repress translation $[2,99]$. Subsequent studies in C. elegans and zebrafish showed that miRNAs also promoted the degradation of their target mRNAs [100], but the mechanism of mRNA decay was independent of endonucleolytic cleavage, which was different from that of plant miRNAs. In animals, there are normally three steps in miRNA-mediated mRNA decay. The first step is deadenylation. The miRNAs induce poly(A) shortening by recruiting two deadenylase complexes, carbon catabolite repressor (CCR)4-negative on TATA (NOT) and poly(A)-nuclease (PAN)2-PAN3, onto target mRNAs through GW182 (glycine-tryptophan protein of $182 \mathrm{kDa}$ ) proteins (trinucleotide repeat containing (TNRC)6 in mammals and GW182 or Gawky in Drosophila) $[98,101]$. It is worth noting that GW182 proteins play a central role in animal miRNA pathway and function as flexible scaffolds to bridge the interaction between Ago proteins and downstream effector complexes, such as CCR4-NOT and PAN2-PAN3. In addition to deadenylases recruitment, GW182 proteins also promote the dissociation of poly(A)-binding protein (PABP), which could enhance the accessibility of the poly $(\mathrm{A})$ tail to deadenylases, thereby increasing the efficiency of deadenylation [102]. The second step is decapping via the decapping protein (DCP)2, which requires additional cofactors for full activity or stability. These cofactors include DCP1, enhancer of decapping (EDC)3, EDC4 and DEAD box helicase 6 (DDX6; also known as Dhh1, RCK, p54 and Me31B in different species) [103]. Finally, deadenylated and decapped mRNAs are degraded by the major cytoplasmic nuclease $5^{\prime}$-to-3' exoribonuclease (XRN)1 [98].

\section{miRNA-mediated mRNA decay in plants}

In contrast to animal miRNAs, plant miRNAs cannot promote deadenylation [104]; instead, they execute cleavage of target mRNA, which occurs at a precise position. This so called "slicing" is carried out by the P-element induced wimpy testes (PIWI) domain of Ago proteins, which forms an RNase H-like fold and exhibits endonuclease activity. The endonuclease activity of PIWI domain has been experimentally confirmed for Arabidopsis Ago1 [56, 105], as well as Ago2 [106], Ago4 [107], Ago7 [108] and Ago10 [109]. Upon slicing, two mRNA fragments are generated: one is $5^{\prime}$ fragment which is protected at its $5^{\prime}$ end by the cap structure with an unprotected $3^{\prime}$ end, and the other is $3^{\prime}$ 'fragment possessing an exposed $5^{\prime}$ end and a poly(A)-protected $3^{\prime}$ end. The two resulting fragments need to be cleared away swiftly, so that the RISC can move on to the next target. In Arabidopsis, XRN4, a 5'-to-3' exoribonuclease, is responsible for degrading the $3^{\prime}$ fragments because accumulated abundance of 3 ' fragments has been found in a loss-of-function mutant of XRN4 [110]. For the removal of the resulting $5^{\prime}$ fragments, there are different pathways that might contribute. Similar to 3' fragments, the $5^{\prime}$ cleavage fragments can be degraded by XRN4. Additionally, the cytoplasmic exosome may also play a role, as its cofactor's subunits, such as superkiller (SKI)2, SKI3 and SKI8, are required for the degradation of RISC-generated 5' fragments [111]. Furthermore, the 3' end of the $5^{\prime}$ fragment is frequently uridylated by HEN1 Suppressor (HESO)1 [112], which can accelerate the degradation of $5^{\prime}$ fragment.

\section{miRNA-mediated translational repression in animals}

Over the last few years, although considerable progress has been achieved in elucidating the biochemistry, biology and genomics of miRNA-directed mRNA regulation, the detailed mechanism of translational repression remains intensely debated. Broadly divided, translation includes three steps: ribosome initiation, elongation and termination. Interestingly, there is evidence for both initiation and post-initiation repression. With the advent of the ribosome profiling method, which allows accurate measurements of translation efficiencies, it is now accepted that inhibitory mechanisms occurring post-initiation could be ruled out [98]. The emerging consensus in this field is that miRNAs inhibit cap-dependent translation at initiation [113], but the precise molecular mechanism for this is ambiguous [114]. Translation initiation begins with eukaryotic translation initiation factor (eIF)4F complex binding to the cap structure of mRNA. EIF4F complex is comprised of the cap-binding protein eIF4E, the RNA helicase eIF4A and the scaffolding protein eIF4G, the latter of which interacts with both eIF4E and eIF4A. Proposed 
mechanisms for miRNA-mediated translational repression include GW182-mediated PABP displacement [102, 115], recruitment of the translational repressors through GW182 [116-119] and dissociation of eIF4A from eIF4F complex [120-122].

\section{a. GW182-mediated PABP displacement}

GW182 proteins induce not only deadenylation and subsequent mRNA decay, but also translational repression [123]. PABP, which binds to the $3^{\prime}$ poly(A) tail of mRNAs, stimulates translation by stabilizing binding of eIF4F complex to the cap structure through interaction with eIF4G. Structural studies have revealed that GW182 proteins are capable of directly interacting with the C-terminal mademoiselle (MLLE) domain of PABP through PABP-interacting motif (PAM)2, therefore restraining PABP. Intriguingly, recent findings have demonstrated that miRNA promotes the dissociation of PABP from target mRNAs in a deadenylation-independent manner [102]. This phenomenon fits the proposed model positing that GW182-mediated displacement of PABP from the poly(A) tail breaks the 'closed-loop' structure formed by the interaction between eIF4G and PABP, thereby repressing translation initiation [124].

b. Recruitment of the Translational repressors through GW182

Through the CCR4-NOT complex, GW182 recruits downstream translational repressors, such as DDX6 or eIF4E transporter (4E-T) onto target mRNAs. DDX6 is known as a decapping activator but can also function in translational repression [125]. In mouse embryonic stem cells, DDX6 is shown to be recruited onto the miRNA targets through interacting with mammalian hyperplastic discs protein EDD (E3 ligase identified/isolated by differential display), which binds to GW182 proteins in the Argonaute-miRNA complexes [126]. More recent studies have also suggested that 4E-T, an eIF4E-binding protein, could be recruited onto the CCR4-NOT complex to suppress translation through DDX6, PATL (PAT1-like protein)1 or LSM (Sm-like domain-containing protein)14 [118, 119]. However, questions such as which step in translation is blocked by these repressors require further characterization.

\section{c. miRNA-mediated dissociation of eIF4A}

EIF4A RNA helicases are translation initiation factors that unwind secondary structures within 5' UTR of mRNA, allowing the $43 \mathrm{~S}$ pre-initiation complexes (PIC) to scan the 5' UTR towards the start codon. Some recent studies have provided evidence that miRNAs could also repress translation via displacement of eIF4A from the cap-binding complex eIF4F, which blocks the 43S PIC recruitment or ribosomal scanning in vitro [120-122]. However, this model remains verification by direct evidence.

\section{miRNA-mediated translational repression in plants}

Plant miRNAs were initially supposed to silence target mRNAs only through endonucleolytic activity of Ago proteins. Strikingly, GW182 protein, the core component required for the miRNA-mediated translational repression in animals, is lacking in plants and its homolog proteins have not been found so far. However, the disproportional effects of miRNAs on target gene expression at the transcript versus protein level implied that plant miRNAs could induce translational repression in addition to target cleavage [127-129]. Early examples of miRNA-mediated translational inhibition in plants were Apetala (AP)2 and squamosa promoter binding protein-like (SPL)3 regulated by miR172 and miR156/7, respectively $[127,128]$. When miR172 and miR156/7 accumulated abnormally, AP2 and SPL3 were altered at the protein levels compared with those of the wild-type, while their transcript levels were comparable. Similar observations were subsequently made for other miRNAs, including miR159 [130], miR164, miR165/6 [131], miR171, miR395, miR398 and miR834 [78]. Known factors involved in the translational repression comprise the microtubule-severing enzyme katanin1 (KTN1), the decapping activator Ge-1 homolog varicose (VCS) [78], the GW-repeat protein SUO [132], the ER membrane protein altered meristem program (AMP) 1 and its homolog, like AMP (LAMP)1 [131]. Currently, it is far from clear how these factors exert their functions in the miRNA pathways of plant and how miRNA-mediated translational repression is regulated.

Taken together, the biogenesis and acting mechanism of miRNAs display a high degree of similarity between animals and plants even though there actually are several subtle differences.

\section{Diet/plant-derived miRNAs in animals}

In fact, the natural uptake of diet-derived miRNAs or dsRNAs has been known to be biologically effective in a wide range of lower eukaryotes or invertebrates [31]. In 1998, it was first discovered that sRNAs found in dietary material could influence gene expression of ingesting organisms in C. elegans through the process of RNA interference [133]. Since then, it has been demonstrated that various invertebrate organisms could acquire sRNA molecules from diverse dietary sources by being orally exposed to dietary material containing either in vitro synthesized dsRNA [134, 135] or artificially expressed dsRNA of plant [136] or bacteria [137]. Continuing 
evidence has consistently shown that uptake of sRNA from environmental sources, including diet, is feasible in simpler metazoan organisms.

Interestingly, some recent evidence suggests that a similar phenomenon might occur in human and other mammals. The revolutionary report by Zhang et al. claimed that diet-derived plant miRNAs were found in the circulation and organs of human and mice, and they were sufficient and efficient to regulate human mRNAs [28]. Although it was earlier known that exogenous miRNAs could be detected in systemic fluids [138-141], this was the first evidence showing that a diet/plant-miRNA, namely rice-derived miR168a, was capable of regulating gene expression in its recipients. Notably, due to 2'-O-methylation on the terminal nucleotides, plant miRNAs are highly resistant to periodate oxidation. This characteristic structure of plant miRNAs renders authors feasibility and reliability to clearly distinguish plant-originated miRNAs from those of animals. In their report, rice-derived miRNAs were shown to target low-density lipoprotein receptor adapter protein (LDLRAP)1, a gene involved in cholesterol metabolism [28]. Functional studies in vitro and in vivo demonstrated that the binding of miR168a to LDLRAP1 mRNA inhibited LDLRAP1 expression in liver cells, and consequently decreased low-density lipoprotein (LDL) removal from the blood [28]. It is therefore proposed that intestinal epithelial cells could absorb plant miRNAs in food and package miRNAs into microvesicles (MVs) to shelter from degradation and subsequently release miRNAs into the circulation. The liberated miRNAs were then delivered via the blood stream to various tissues/ cells where they modulated target gene expression [28]. In addition, they also implied that plant miRNAs could use even mammalian Ago2 protein to form their own RISC and perform their functions similar to those of mammalian miRNAs [28]. Though exciting, several groups have subsequently presented more intricate evidence arguing the possibility of plant miRNA uptake and their potential influences on biological processes in animals (Tables 1 and 2).

\section{Supporting evidence (Table 1)}

Following Zhang's work, a study by Liang et al. showed that miR172 from cabbage (Brassica oleracea) was detected in the blood, spleen, liver and kidney of mice fed with plant total RNAs [142]. Moreover, they found that sRNAs could survive for $36 \mathrm{~h}$ or longer in blood and fecal samples in the presence of degrading enzymes, indicating the potential stability of sRNAs. In 2015, another group published their results obtained from volunteers drinking watermelon juice or eating mixed fruits (watermelon, banana, apple, orange, grape, mango and cantaloupe) [143]. Using real-time reverse transcription polymerase chain reaction (RT-qPCR) and northern blotting, they identified 10 plant miRNAs in human plasma at high basal levels [143]. By conducting a kinetics study, they proved that the absorption of plant miRNA was not a technical artifact or contamination, but a real physiological event. Importantly, they established a standard operation procedure for measuring plant miRNAs in human and animal plasma, which would promote investigations in this nascent field.

Studies supporting biologically relevant uptake of plant-originated miRNAs have focused on miR2911, a honeysuckle-derived miRNA [29, 144-147]. Honeysuckle is a well-known Chinese herb widely applied in the prevention and control of epidemic diseases. Modern pharmacological study has confirmed that honeysuckle has a broad spectrum of antimicrobial activity [148]. Zhang et al. [29] showed that continuous drinking or gavage feeding the decoction of boiled honeysuckle led to the elevation of miR2911 in the sera and lungs of mice. More interestingly, miR2911 was not degraded during the honeysuckle boiling process [29]. This phenomenon was consistent with a simulation study, in which dietary plant miRNAs were stably present in intact form after storage, processing, cooking and early digestion [149]. Subsequent functional studies of miR2911 demonstrated that miR2911 targeted and inhibited various IAVs, including H1N1, H5N1 and H7N9 [29]. They also demonstrated that the bulk of miR2911 in mouse peripheral blood was detected in MVs fraction and largely associated with the Ago2 complex, implying miR2911 might exert its function through the same MV-mediated pathway. Concerning the stability of miR2911, it was proposed to rely on its unique sequence and high GC content. More insightful knowledge of miR2911 was put forward by four independent studies from Yang et al. [144-147]. Consistently, Yang reported a significant increase of plant miR2911 in the sera and urine of the honeysuckle decoction-consuming mice [144]. Moreover, the damaged guts resulting from cisplatin also led to enhanced miRNA retention in the mouse circulation [144], which further verified the possibility of miRNAs transferring from plant to animals. Yang' work $[145,146]$ also proposed that the high stability of circulating miR2911 was associated with neither exosomes nor Ago complex. Additionally, they showed that unlike most of plant-derived biomolecules, miR2911 was atypical as their abundance was positively correlated with the degradation of plant foods and rRNAs (ribosomal RNAs), and their biogenesis was Dicer independent [147]. The above information suggests that miRNAs may be one of the hidden but bioactive components in herbal medicines.

The potentials for therapeutic use of plant miRNAs were also supported by studies from other labs [150- 


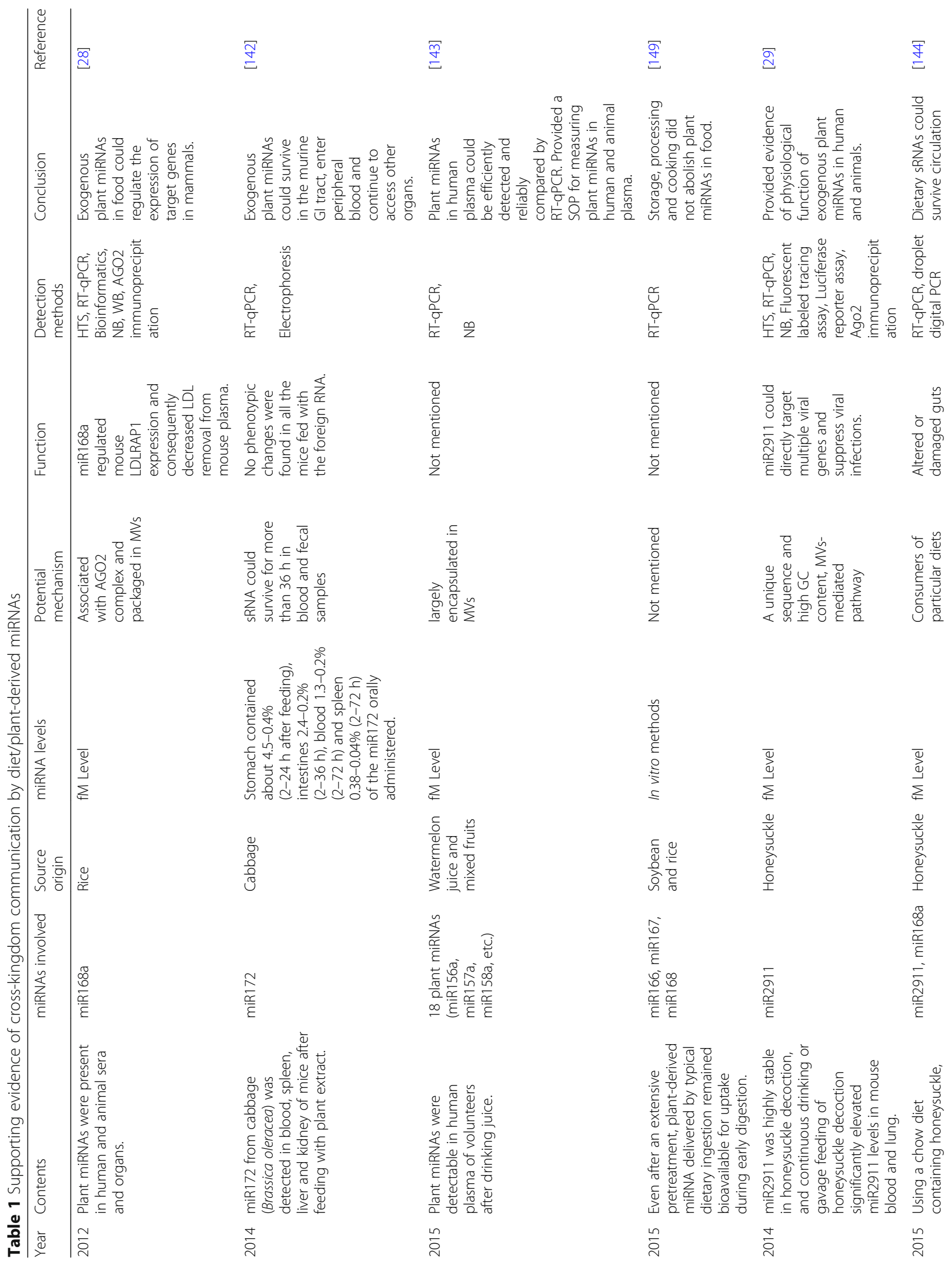




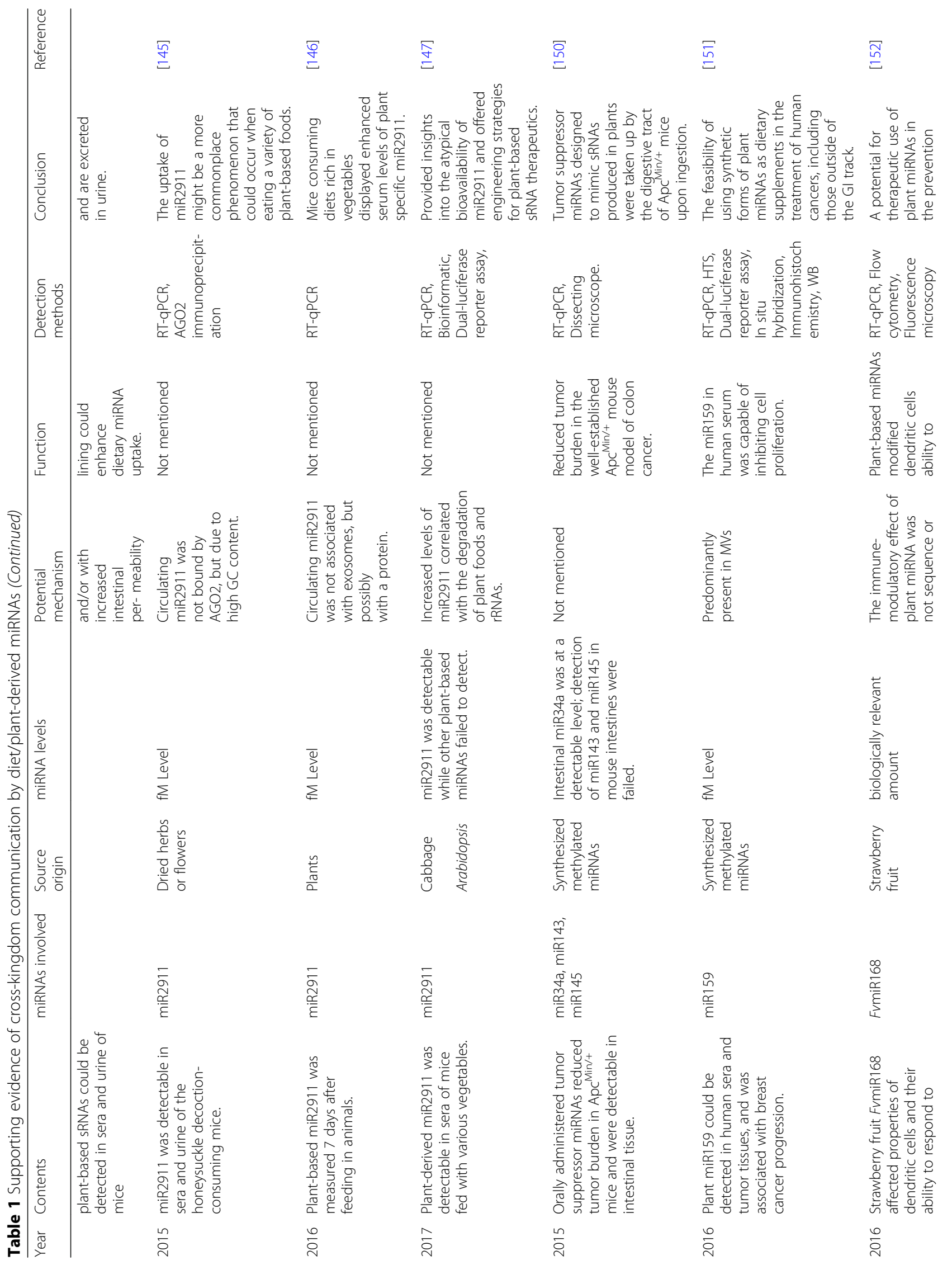




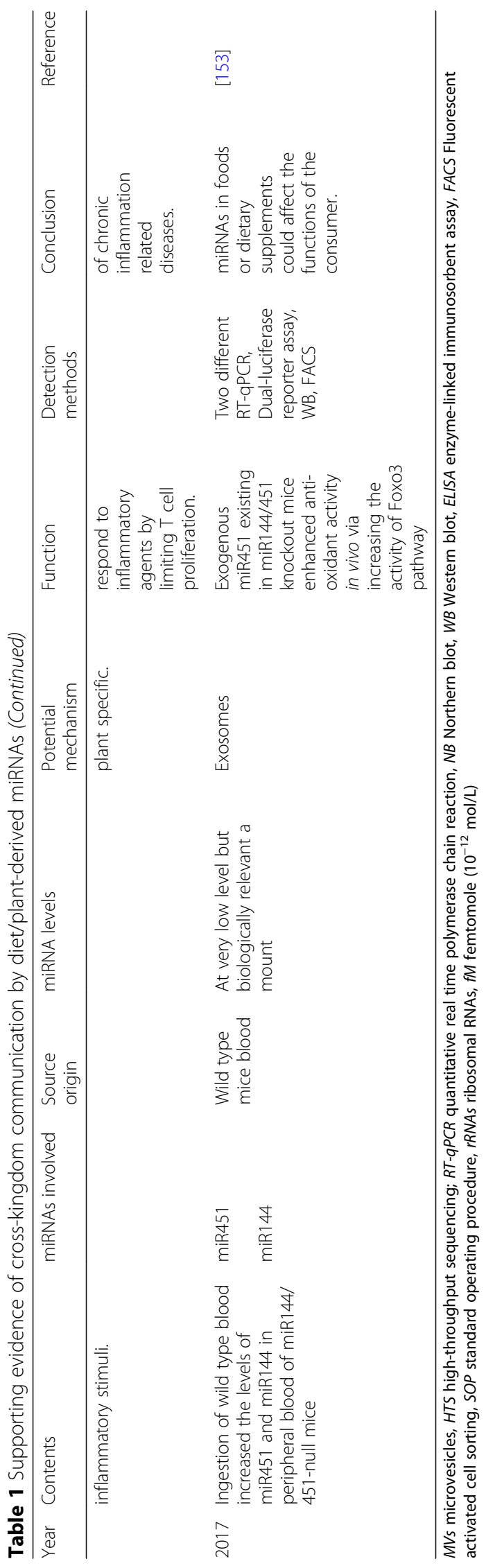




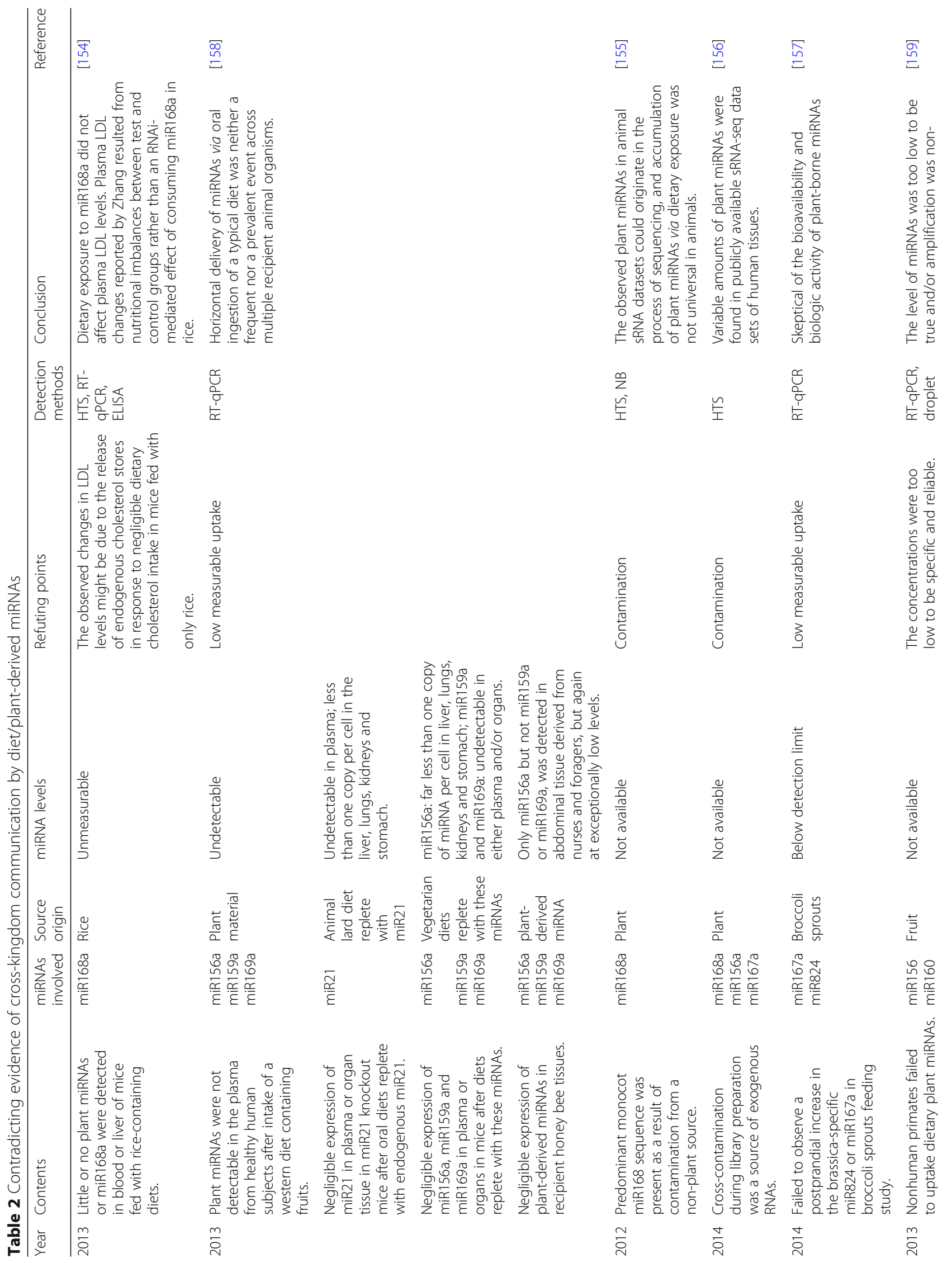




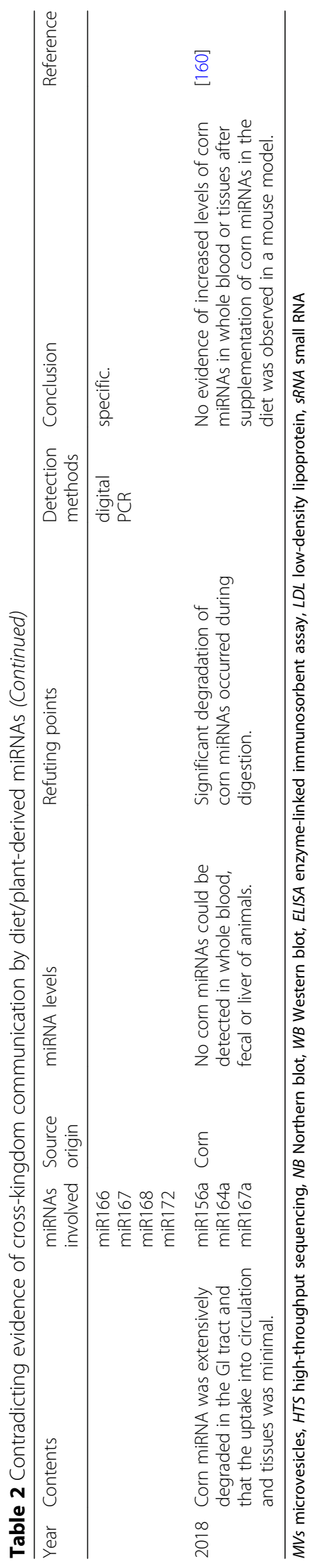


153]. One group reported that the oral administration of a cocktail of three tumor suppressor miRNAs designed to mimic sRNAs produced in plants reduced tumor burden in a mouse model of colon cancer [150]. Another group showed that plant-derived miR159 could be predominantly detected in Western human sera and tumor tissues, and was associated with the incidence and progression of breast cancer [151]. More importantly, further data revealed that synthetic forms of plant miR159 significantly reduced breast tumor growth in mice by targeting sequence of the 3' UTR of transcription factor (TCF)7 mRNA. Their study suggested that plant-engineered miRNA designed for specific targets possessed a significant potential in clinical therapeutic applications [151]. Supportively, Cavalieri et al. [152] demonstrated that strawberry miRNAs could act as ligands and bind to toll-like receptor (TLR)3 on dendritic cells, therefore modulating their responses to inflammatory agents. This study consolidated the therapeutic capacity of plant miRNAs in the prevention of human disorders. Using miR144/451 gene knockout mouse model, a more recent finding by Wang et al. [153] showed that exogenous miR451 were able to enter the circulation through digestive system of mouse to enhance anti-oxidant activity in vivo via Foxo3 pathway. These studies suggest that miRNAs derived from plants or diets can not merely transfer to animals effectively, but exert their gene-regulatory function in a cross-kingdom manner.

\section{Contradicting evidence (Table 2)}

Along with above mentioned studies supporting dietary uptake and biological function of plant-originated miRNAs, paramount efforts have been made arguing the rationality of this issue, including direct replications of Zhang's work. Dickenson et al. [154] attempted to validate the original work of Zhang [28] but failed to find consistent evidence of dietary uptake of miR168a after rice feeding. In their study, mice were grouped into standard chow, a nutritionally sufficient diet containing $41 \%$ rice or raw rice, respectively. Unfortunately, little or no plant miRNAs or miR168a were detected in the blood or liver of mice fed with rice-containing diets. Interestingly, consistent with the result of Zhang [28], the levels of LDL in the mice liver were indeed increased in mice fed with uncooked rice, but the expression of LDLRAP1 remained unchanged across all three experimental groups. They therefore proposed that the increase in LDL levels reported by Zhang et al. was a result of short-time nutritional impact and possibly the release of endogenous cholesterol stores when cholesterol intake was insufficient in this experimental condition [154]. Using recently developed deep sequencing technologies and bioinformatic analysis, another two groups $[155,156]$ found variable amounts of plant
miRNAs in public animal sRNA datasets. Among them, the most abundant molecule was miR168a, having a sequence typical of monocot plant species. Additionally, Zhang et al. [155] also conducted experiments with controlled insect feeding, in which plant-derived miRNAs including miR168a were also found in datasets for insects that did not feed with monocot plants. Based on experimental evidences proposing that cross-contamination during library preparation was an unnoticed source of exogenous miRNAs, Tosar et al. [156] directly pointed out that the underlying cause of findings achieved by Zhang and colleges was a contamination of miRNAs, instead of miRNAs transmitted from other kingdoms.

Besides, negative results regarding cross-species transmission of plant-derived miRNAs were obtained in various insects and animals [157-160]. Study by Baier et al. demonstrated that plant-borne miRNAs might be not bioavailable in human as the brassica-specific miR824 and plant-specific miR167a could be barely detectable in blood of four randomly selected participants after consumption of a broccoli sprout meal [157]. Consistently, Snow et al. found a substantial level of plant miR156a, miR159a and miR169a in a diet commonly consumed by human, mice and honeybees [158]. However, after ingestion of fruits full of listed plant miRNAs, all of investigated subjects did not carry detectable plasma levels of those molecules [158]. Similar negative findings were shown for Macaca nemestrina, a non-human primate model employed by Witwer et al. [159] when examining their responses to dietary intake of a miRNA-rich plant. The levels of certain plant miRNAs in blood were evaluated before and after (1, 4 and $12 \mathrm{~h}$ ) ingestion by RT-qPCR and droplet digital PCR. Although they observed low concentrations of some investigated plant miRNAs, the amplification was variable and might be non-specific. Recently, another research group aimed to detect corn miRNAs in cecum, feces, liver and in whole blood of mice [160]. Similar to the studies discussed above, Huang and colleagues [160] failed to identify corn miRNAs in the mentioned organs following supplementation of corn miRNAs in animal diet or gavage to the animals. Further in vitro digestion system suggested that degradation of miRNAs was responsible for the observations [160]. Taken together, these independent investigations certified little or low measurable uptake of plant miRNAs in human and other mammals after consumption of plants or plant miRNAs and unfolded crucial problems existing in the study of cross-kingdom transmission of miRNAs.

The main stream of pitfalls claimed by dissenters is the reliability and sensitivity of techniques commonly applied in the study of cross-kingdom transmission of miRNAs. Firstly, contamination of endogenous miRNAs 


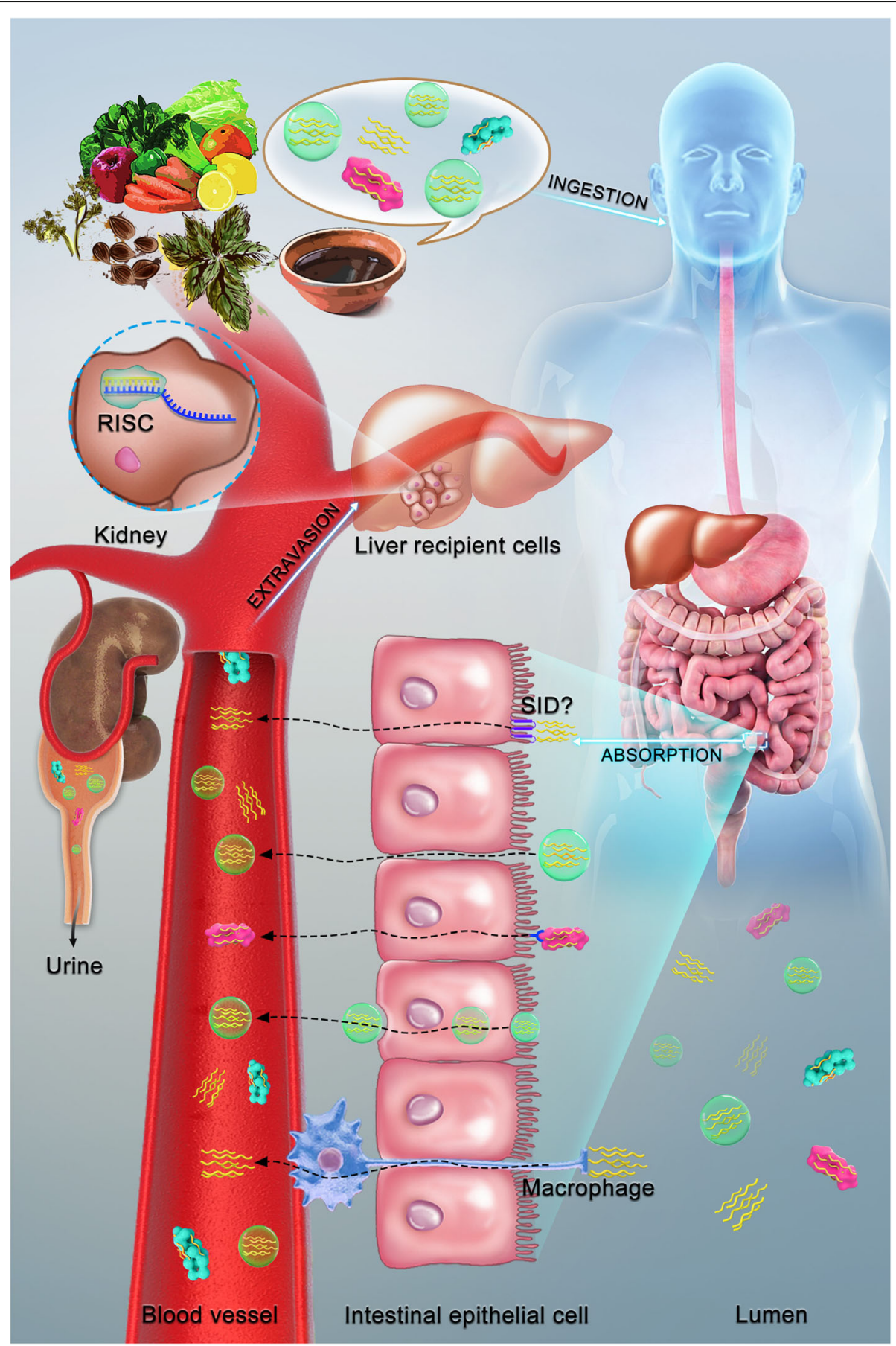

Fig. 2 A schematic model of diet/plant-derived miRNAs journey from nature to human recipient cells. Plant-based foods or herb materials like in the form of decoctions are abundant in miRNAs, which are potentially packaged into vesicles or incorporated with proteins. When ingesting these plant materials, different forms of diet/plant-derived miRNAs could be released and subsequently transferred to the intestinal epithelial cells via different possible mechanisms, 1) by SID-like transporters; 2) vesicle-mediated transcytosis; 3) ribonucleoprotein complexes-mediated endocytosis; 4) through immune cells present in the gut barrier; 5) or diffusion in the space between epithelial cells. Being absorbed by gut lining, miRNAs enters circulation. Once delivered to targeted cells in organs such as liver and engulfed, diet/plant-derived miRNAs are liberated and subsequently execute their functionalities. If unfortunate, these circulating miRNAs may be filtrated and excreted at the kidney prior to their access to recipient cells

from recipients or study platforms could not be ruled out. Thus, a standard and consensus experimental protocol, which truly makes plant and animal miRNAs distinguishable, and accurate experimental performance in the absence of any known sources of plant contaminations are both highly recommended. Secondly, noises 
of background signals during RT-qPCR or artifacts from sequencing procedure raise great concerns, especially when low signals from target miRNAs were detected. This technical flaw necessitates reliable negative control groups and double-confirmation of positive results using independent methodologies. Thirdly, selection of relevant experimental controls gives rise to some discrepancies. A comprehensive design, application and analysis of more than one control group may assist to reduce the disagreement. Lastly, direct evidence of plant-originated miRNAs crossing GI may compromise the divergences existing in this field.

\section{A long travel: Delivery of diet/plant-derived miRNAs}

\section{(Fig. 2)}

Apart from controversies on whether diet/plant-derived miRNAs are sufficient and efficient to execute their regulation of gene expression in recipient cells in a cross-kingdom manner, concerns regarding how these molecules can survive the GI tract, enter circulatory system and ultimately recognize their targets have also been raised. The first crucial point is the stability of active diet/plant-derived miRNAs in the preparation process as well as in mammalian circulation. In the case of miRNAs from rice or herbal medicines, high-temperature processing such as cooking or boiling are unavoidable, in which miRNAs may be largely destroyed. In addition, the existence of RNases, phagocytosis and extreme $\mathrm{pH}$ in GI tract as well as blood circulation may also destabilize ingested miRNAs prior to their access to recipient cells. Fortunately, the presence of 2'-O-methylation on the 3'-terminal nucleotide seems to endow diet/ plant-derived miRNAs with enhanced stability, ensuring their regulatory activity $[50,54]$. Otherwise, the increased stability may also be explained by the unique sequence and GC content of plant miRNAs. The most prominent example is honeysuckle-derived miR2911 [29], as mentioned above. Beyond the innate capacity of diet/plant-derived miRNAs, the supposed existence of miRNA carriers is more likely to protect plant/diet-derived miRNAs in extremely harsh conditions and subsequently assist their translocation into mammals [30, 161]. According to their origin, size and mechanism of formulation, these carriers can be divided into: (1) exosomes $(50-100 \mathrm{~nm})$, which are derived from the endosomal membrane; (2) microvesicles $(20 \mathrm{~nm}-1 \mu \mathrm{m})$, which are released from the plasma membrane during cell stress and (3) apoptotic bodies (1-5 $\mu \mathrm{m})$, which are liberated in response to apoptotic stimuli [162, 163]. It has been reported that above listed vesicles could protect extracellular miRNAs against RNases on one hand, and on the other hand facilitate their transfer within the host [164, 165]. In 2014, Mu et al. [166] characterized edible plant derived exosome-like nanoparticles
(EPDENs), in which proteins, lipids and miRNAs have been identified. Their data suggested that EPDENs were uptaken by intestinal macrophages and stem cells when orally administrated, and actively exerted biological functions on the recipient cells. This finding potentially implied EPDENs as possible mediators in the crosstalk between the plant kingdom and mammalian cells. Additionally, stabilization of extracellular miRNAs was proved to be associated with RNA-binding proteins, such as nucleophosmin 1 [167], high-density lipoproteins (HDL) [168] and Ago-2 [169].

Another key issue is how diet/plant-derived miRNAs pass through the GI tract. By using an ex vivo everted gut sac to simulate the real physiological condition, a recent study by Luo et al. reported that exogenous plant miRNAs in food could cross the intestinal barrier and enter bloodstream of porcine, although the underlying mechanisms were unexplored [170]. In invertebrates, the transmembrane systemic RNA interference defective protein (SID)-1 allows sRNAs to be transported into cells outside of the digestive tract in C. elegans [171]. Meanwhile, SID-2 is another recently identified transmembrane protein in C. elegans. In contrast to the ubiquitous expression of SID-1, SID-2 is expressed in the intestine luminal membrane and might mediate the endocytosis of sRNAs from the lumen [172]. Notably, two homologous proteins of SID-1, namely SID-1 transmembrane family member (SIDT) 1 and SIDT2 exist in most vertebrates, which may be involved in sRNA uptake in human $[173,174]$. It is commonly believed that intestinal epithelial cells (IECs) form a continuous physical barrier in mammals, which provides a severe impediment against the uptake of environmental sRNAs [175]. Evidence to date defines two possible modes of transport across the digestive tract epithelium, either transcellular or paracellular. During the transcellular pathway, miRNAs could cross the intestine via transcytosis or protein transporters. Alternatively, some vesicles such as microvesicles or exosomes could also fuse with the epithelial cell membrane facilitating transportation. Additionally, for ribonucleoprotein complexes containing sRNAs, endocytosis has been shown to play a role in the uptake of sRNAs from dietary sources. A relevant example showed that miRNAs complexed with HDL can be endocytosed after interaction with HDL receptor scavenger receptor class B type I (SRBI) [168]. On the other hand, the paracellular pathway allows diffusion of molecules in the space between epithelial cells. This mode of transfer is usually under a delicate regulation of intercellular tight junctions [175]. Supportively, Yang et al. [144] proposed that intestinal injury or the microbiome within the GI tract could have a role by affecting the permeability of GI tract and further enhanced the delivery of dietary sRNAs into circulation. In addition to 
intestinal epithelial cells [175], the mammalian digestive tract is colonized by a variety of immune cells, which are able to trap sRNAs and other molecules on one side and release them on the other, with or without movement of the cell to a new location [176].

To sum up, the current model of miRNAs pathway from food sources to recipient cells may be built as follows: plant materials can be mechanistically crushed by oral activity and partially digested by various enzymes in our mouth/stomach. During these processes, plant miRNAs are released from destroyed cells and transferred to the intestinal epithelial cells, where plant miRNAs could be selectively incorporated with proteins or packaged into vesicles. Being absorbed by gut lining, miRNAs enters circulation. Once delivered to targeted cells and engulfed, plant miRNAs are liberated and subsequently execute their functionalities.

\section{miRNAs as novel hormone-like messengers}

Diet/plant-derived miRNAs described above seem to act in a hormone-like fashion. Hormones are chemicals secreted from glands and enter the bloodstream where they circulate until exerting an effect on a downstream target cell. Both animal and plant cells use hormones for long-distance communication. Recent findings suggest circulating miRNAs as a novel form of cell-to-cell communicator $[161,177]$. This viewpoint is reflected by the fact that circulating miRNAs are secreted by donor cells into circulation, then stably transported to other parts of the body and up-taken by recipient cells [178]. The reveal of hormone-like actions of miRNAs in recipient cells has driven this notion forward. Skog et al. showed that glioblastoma-specific proteins and RNAs (containing miR-21) were released in MVs and were converted by recipient normal cells into functional signals to stimulate proliferation and promote tumor progression [179]. In another study, miR-335 was indicated to modulate immune responses during the unidirectional transfer from $\mathrm{T}$ cells to antigen-presenting cells (APC) [180]. These results highly suggest that secreted miRNAs represent a novel mode of signaling for long-distance transportation of messages, by which donor cells can influence gene expression of recipient cells, and thus impact physiological and pathological processes.

With the discovery of circulating miRNAs in human body fluids, a more intricate level of cellular communication and regulation is introduced, and interactions between hormones and miRNAs are starting to emerge. Considering the significance of miRNAs and their involvement in various biological processes, it is not surprising that miRNAs are participating in the synthesis [181, 182] and secretion [183] of several hormones. Likewise, the expression of several miRNAs is in turn under regulations of hormones.
A finding has reported the role of miRNAs in adrenal cell physiology [184]. Angiotensin (Ang)II, the end product of the renin-angiotensin system, has been confirmed to up-regulate the expression of miR-21 in human adrenocortical cells (H295R) [184]. Notably, in microarray analysis of more than 200 miRNAs, only the expression level of miR-21 has been up-regulated by Ang II, and its overexpression caused an increase in aldosterone secretion and cell proliferation [184]. Another study showed that hormones could regulate miRNAs in the testis, ovary, and adrenal glands steroidogenic cells and the expression level of adrenal miRNAs appears to be regulated by more than one hormone [185]. Thyroid hormones $(\mathrm{TH})$, which are known to be essential for the development, differentiation and maintenance of metabolic balance in mammals, might alter miRNA expression which could, in turn, alter mRNA abundance [186]. In Dong's report, 40 significantly altered miRNAs has been detected in the livers of hypothyroid mice [186]. $\mathrm{TH}$ regulation of miRNAs was also supported by recent studies on miR-181d in hepatic cells [187]. Based on their data, two novel TH-regulated target genes that were downstream of miR-181d signaling, caudal type homeobox (CDX)2 and sterol O-acyltransferase (SOAT)2, have also been identified and characterized. Furthermore, the miR181d/CDX2/SOAT2 cascade was likely to contribute to this TH-dependent change in hepatic and systemic lipid metabolism [187]. In hypothalamus and pituitary, mounting miRNAs have been implicated as communicators interacting with hormones [188-190]. MiR-375 has been shown to inhibit the expression of proopiomelanocortin (POMC) and affect the synthesis and secretion of pituitary hormones [188]. Investigation of miR-24 has revealed its role in controlling the level of oxytocin, which was produced in the hypothalamic paraventricular and supraoptic nuclei [189]. Another study has demonstrated that miR-361-3p was involved in the secretory regulation of follicle-stimulating hormone (FSH) in porcine anterior pituitary cell [190].

Apart from crosstalk between hormones and miRNAs in mammals, their interactions appear to be rational in plants. The expression level of miR159 has been shown increased by abscisic acid (ABA), a plant hormone involved in bud and seed dormancy, root growth, leaf senescence and abscission, stomata opening and stress protection [191]. Besides, miR159, miR319 and miR166 have been proven to be involved in the plant hormone gibberellin pathway [192-194]. Hormone modulation of miRNAs in plant has been exemplified in the case of auxin. To keep normal development, change of exogenous auxin levels resulted in alterations of miR168 and miR169 levels [195, 196]. Another example of this scenario involves miR172 and miR319, which were 
discovered to be down-regulated when subjected to cytokinin 6-benzylaminopurine (6-BA) treatment [195]. Additionally, in the same report, Liu et al. has observed decreased levels of miR159 and miR394 when subjected to ethylene treatment in rice [195].

Together, miRNAs may act in a hormone-like fashion, and hormones and miRNAs are mutually regulated in both kingdoms. The interplay between the hormones and miRNAs may shed substantial light on whether hormones in human have any influence on diet/plant-derived miRNAs and how diet/plant-derived miRNAs coordinate with human hormones to fulfill their entire function.

\section{Conclusions and future perspectives}

As potent intracellular mediators, functional significance of miRNAs has been widely validated. Evidence from animals showing inter-species gene regulation mediated by miRNAs derived from evolutionarily distant species suggests miRNAs as an alternative nutrient. Likewise, existence of miRNAs in herbal plants represents an extended scope of ingredients that may intentionally impact human health. In light of the phenomenon that synthetic supplements of phytochemicals do not usually have the same efficacy as complex herb materials, cross-species transmission of dietary miRNAs from plants to human may provide additional clues for evaluating the active therapeutic components of herbs.

At current stage, identification of more transmitted miRNAs in our diet and medical plants may greatly assist the enrichment and significance of food/herbal miRNA databases. However, the exact processes of plant-originated miRNAs crossing GI remain to be further validated. To fulfill the above, a consensus justifying the methodology of miRNA verification should be reached. Since mammals do not possess amplification pathways as C. elegans, quantification of biologically meaningful abundance of diet/plant-derived miRNAs in human body appears indispensable. In addition, mechanisms of how diet/plant-derived miRNAs are incorporated into the host RISC and further convey the silencing effects require delicate explanation. If these should be unrealistic, the exact mechanisms of intestinal absorption, bioavailability, tissue distribution and function of exogenous miRNAs could be envisaged, which though constitutes the major challenges will facilitate the development of both nutrition and medicine.

\footnotetext{
Abbreviations

4E-T: EIF4E transporter; 6-BA: 6-benzylaminopurine; ABA: Abscisic acid; Ago: Argonaute; AMP: Altered meristem program; Ang: Angiotensin; AP: Apetala; APC: Antigen-presenting cells; C. elegans: Caenorhabditis elegans; CCR: Carbon catabolite repressor; CDS: Coding sequence; CDX: Caudal type homeobox; CSD: Copper/zinc superoxide dismutase; DCL: Dicer-like; DCP: Decapping protein; DDX: DEAD box helicase; DGCR: DiGeorge syndrome critical region; dicing bodies: D-bodies; dsRNA: Double-stranded
}

RNA; EDC: Enhancer of decapping; EDD: E3 ligase identified/isolated by differential display; elF: Eukaryotic translation initiation factor; EPDENs: Edible plant derived exosome-like nanoparticles; FSH: Follicle-stimulating hormone; Gl: Gastrointestinal; GTP: Guanosine triphosphate; GW182: Glycine-tryptophan protein of 182 kDa; Hasty: HST; HDL: High-density lipoproteins; HEN: Hua Enhancer; HESO: HEN1 Suppressor; HITS-CLIP: High-throughput sequencing together with UV-crosslinking and immunoprecipitation; IAV: Influenza A virus; IECs: Intestinal epithelial cells; KTN: Katanin; LAMP: Like AMP; LDL: Lowdensity lipoprotein; LDLRAP: Low-density lipoprotein receptor adapter protein; Loqs: Loquacious; LSM: Sm-like domain-containing protein; m7G: 7methylguanosine; miRNA: MicroRNA; MLLE: Mademoiselle; mRNA: Messenger RNA; MV: Microvesicle; NOT: Negative on TATA; PABP: Poly(A)-binding protein; PAM: PABP-interacting motif; PAN: Poly(A)-nuclease; PATL: PAT1-like protein; PIC: Pre-initiation complexes; PIWI: P-element induced wimpy testes; Pol: Polymerase; POMC: Proopiomelanocortin; pre-miRNA: Precursor miRNA; pri-miRNA: Primary miRNA; Ran: Ras-related nuclear protein; RISC: RNAinduced silencing complex; RNase: Ribonuclease; rRNA: Ribosomal RNA; RTqPCR: Quantitative real time polymerase chain reaction; SID: Systemic RNA interference defective protein; SIDT: SID1 transmembrane family member; SKI: Superkiller; SOAT: Sterol O-acyltransferase; SPL: Squamosa promoter binding protein-like; SRBI: Scavenger receptor class B type l; sRNA: Small RNA; TCF: Transcription factor; TH: Thyroid hormones; TLR: Toll-like receptor; TNRC: Trinucleotide repeat containing; TRBP: Transactivation-response RNAbinding protein; UTR: Untranslated region; VCS: Varicose;

$\mathrm{XRN}$ : Exoribonuclease

\section{Acknowledgements}

Authors thank Qiuyi Zhang, University of Chinese Academy of Sciences, Shanghai, China for providing the first draft of graphic abstract and stimulating discussions.

\section{Funding}

The laboratory of the authors benefits from ongoing support from the National Natural Science Foundation of China (81573587), the Fundamental Research

Funds for the Central Public Welfare Research Institutes (YZ-1779 and Y-1706).

\section{Authors' contributions}

ZL wrote the manuscript with input from all authors. NL and RX contributed to the final version of this article. All authors read and approved the final manuscript.

Ethics approval and consent to participate

Not applicable.

Consent for publication

Not applicable.

\section{Competing interests}

The authors declare that they have no competing interests.

\section{Publisher's Note}

Springer Nature remains neutral with regard to jurisdictional claims in published maps and institutional affiliations.

\section{Author details}

${ }^{1}$ State Key Laboratory of Medical Molecular Biology, Institute of Basic Medical Sciences, Chinese Academy of Medical Sciences, Peking Union Medical College, Tsinghua University, Beijing 100005, People's Republic of China. ${ }^{2}$ Institute of Basic Theory for Chinese Medicine, China Academy of Chinese Medical Sciences, Beijing 100700, People's Republic of China. ${ }^{3}$ Department of Engineering, Aarhus University, 8000 Aarhus, Denmark.

Received: 7 May 2018 Accepted: 21 September 2018

Published online: 01 October 2018

\section{References}

1. Lee RC, Feinbaum RL, Ambros V. The C. elegans heterochronic gene lin-4 encodes small RNAs with antisense complementarity to lin-14. Cell. 1993; 75(5):843-54. 
2. Wightman B, Ha I, Ruvkun G. Posttranscriptional regulation of the heterochronic gene lin-14 by lin-4 mediates temporal pattern formation in C. elegans. Cell. 1993;75(5):855-62.

3. Reinhart BJ, Slack FJ, Basson M, Pasquinelli AE, Bettinger JC, Rougvie $A E$, et al. The 21-nucleotide let-7 RNA regulates developmental timing in Caenorhabditis elegans. Nature. 2000;403(6772):901.

4. Axtell MJ, Westholm JO, Lai EC. Vive la différence: biogenesis and evolution of microRNAs in plants and animals. Genome Biol. 2011;12(4):221.

5. Perge P, Nagy Z, Decmann Á, Igaz I, Igaz P. Potential relevance of microRNAs in inter-species epigenetic communication, and implications for disease pathogenesis. RNA Biol. 2017;14(4):391-401.

6. Aukerman MJ, Sakai H. Regulation of flowering time and floral organ identity by a microRNA and its APETALA2-like target genes. Plant Cell. 2003;15(11):2730-41.

7. Abbott AL, Alvarez-Saavedra E, Miska EA, Lau NC, Bartel DP, Horvitz HR, et al. The let-7 MicroRNA family members mir-48, mir-84, and mir-241 function together to regulate developmental timing in Caenorhabditis elegans. Dev Cell. 2005;9(3):403-14.

8. Ambros V. MicroRNAs and developmental timing. Curr Opin Genet Dev. 2011;21(4):511-7.

9. Bentwich I. A postulated role for microRNA in cellular differentiation. FASEB J. 2005;19(8):875-9.

10. Onnis A, Navari M, Antonicelli G, Morettini F, Mannucci S, De Falco G, et al. Epstein-Barr nuclear antigen 1 induces expression of the cellular microRNA hsa-miR-127 and impairing B-cell differentiation in EBVinfected memory B cells. New insights into the pathogenesis of Burkitt lymphoma. Blood Cancer J. 2012;2(8):e84.

11. Zhang Z, Xue Z, Liu Y, Liu H, Guo X, Li Y, et al. MicroRNA-181c promotes Th17 cell differentiation and mediates experimental autoimmune encephalomyelitis. Brain Behav Immun. 2018;70:305-14.

12. Brennecke J, Hipfner DR, Stark A, Russell RB, Cohen SM. Bantam encodes a developmentally regulated microRNA that controls cell proliferation and regulates the proapoptotic gene hid in Drosophila. Cell. 2003;113(1):25-36.

13. Rodriguez RE, Schommer C, Palatnik JF. Control of cell proliferation by microRNAs in plants. Curr Opin Plant Biol. 2016;34:68-76.

14. Thompson BJ, Cohen SM. The hippo pathway regulates the bantam microRNA to control cell proliferation and apoptosis in Drosophila. Cell. 2006;126(4):767-74.

15. Chen $Y$, Stallings RL. Differential patterns of microRNA expression in neuroblastoma are correlated with prognosis, differentiation, and apoptosis. Cancer Res. 2007;67(3):976-83.

16. Liu L, Zhang G, Liang Z, Liu X, Li T, Fan J, et al. MicroRNA-15b enhances hypoxia/reoxygenation-induced apoptosis of cardiomyocytes via a mitochondrial apoptotic pathway. Apoptosis. 2014;19(1):19-29.

17. Zhang X, Zhang X, Hu S, Zheng M, Zhang J, Zhao J, et al. Identification of miRNA-7 by genome-wide analysis as a critical sensitizer for TRAIL-induced apoptosis in glioblastoma cells. Nucleic Acids Res. 2017;45(10):5930-44.

18. Boehm M, Slack FJ. MicroRNA control of lifespan and metabolism. Cell Cycle. 2006:5(8):837-40.

19. Poy MN, Eliasson L, Krutzfeldt J, Kuwajima S, Ma X, Macdonald PE, et al. A pancreatic islet-specific microRNA regulates insulin secretion. Nature. 2004; 432(7014):226.

20. Liu G, Zhang S, Li X, Cao L, Fu Z, Yu S. Overexpression of microRNA-132 enhances the radiosensitivity of cervical cancer cells by down-regulating Bmi-1. Oncotarget. 2017;8(46):80757-69.

21. Moradifard S, Hoseinbeyki M, Ganji S, Minuchehr Z. Analysis of microRNA and gene expression profiles in Alzheimer's disease: a meta-analysis approach. Sci Rep. 2018;8(1):4767.

22. Bartel DP. MicroRNAs: target recognition and regulatory functions. Cell. 2009;136(2):215-33.

23. O'Connor RM, Gururajan A, Dinan TG, Kenny PJ, Cryan JF. All roads lead to the miRNome: miRNAs have a central role in the molecular pathophysiology of psychiatric disorders. Trends Pharmacol Sci. 2016;37(12): 1029-44.

24. Liu RH. Health benefits of fruit and vegetables are from additive and synergistic combinations of phytochemicals. Am J Clin Nutr. 2003;78(3):5175-20S.

25. Willett WC. Balancing life-style and genomics research for disease prevention. Science. 2002;296(5568):695-8.

26. Liu RH. Potential synergy of phytochemicals in cancer prevention: mechanism of action. J Nutr. 2004;134(12):3479S-85S.
27. Liu RH. Health-promoting components of fruits and vegetables in the diet Adv Nutr. 2013:4(3):384S-92S.

28. Zhang L, Hou D, Chen X, Li D, Zhu L, Zhang Y, et al. Exogenous plant MIR168a specifically targets mammalian LDLRAP1: evidence of crosskingdom regulation by microRNA. Cell Res. 2012;22(1):107.

29. Zhou Z, Li X, Liu J, Dong L, Chen Q, Liu J, et al. Honeysuckle-encoded atypical microRNA2911 directly targets influenza a viruses. Cell Res. 2015;25(1):39.

30. Xie W, Weng A, Melzig MF. MicroRNAs as new bioactive components in medicinal plants. Planta Med. 2016;82(13):1153-62.

31. Chan SY, Snow JW. Uptake and impact of natural diet-derived small RNA in invertebrates: implications for ecology and agriculture. RNA Biol. 2017;14(4): 402-14.

32. Lee $Y$, Kim M, Han J, Yeom KH, Lee S, Baek SH, et al. MicroRNA genes are transcribed by RNA polymerase II. EMBO J. 2004;23(20):4051-60.

33. Cai $\mathrm{X}$, Hagedorn $\mathrm{CH}$, Cullen BR. Human microRNAs are processed from capped, polyadenylated transcripts that can also function as mRNAs. RNA. 2004;10(12):1957-66

34. Faller M, Guo F. MicroRNA biogenesis: there's more than one way to skin a cat. Biochim Biophys Acta. 2008;1779(11):663-7.

35. Lee $Y$, Jeon K, Lee JT, Kim S, Kim VN. MicroRNA maturation: stepwise processing and subcellular localization. EMBO J. 2002;21(17):4663-70.

36. Lee Y, Ahn C, Han J, Choi H, Kim J, Yim J, et al. The nuclear RNase III Drosha initiates microRNA processing. Nature. 2003;425(6956):415.

37. Denli AM, Tops BB, Plasterk RH, Ketting RF, Hannon GJ. Processing of primary microRNAs by the microprocessor complex. Nature. 2004;432(7014):231.

38. Gregory RI, K-p Y, Amuthan G, Chendrimada T, Doratotaj B, Cooch N, et al. The microprocessor complex mediates the genesis of microRNAs. Nature. 2004;432(7014):235.

39. Han J, Lee $Y$, Yeom K-H, Kim Y-K, Jin H, Kim VN. The Drosha-DGCR8 complex in primary microRNA processing. Genes Dev. 2004;18(24):3016-27.

40. Yi R, Qin Y, Macara IG, Cullen BR. Exportin-5 mediates the nuclear export of pre-microRNAs and short hairpin RNAs. Genes Dev. 2003;17(24):3011-6.

41. Lund E, Güttinger S, Calado A, Dahlberg JE, Kutay U. Nuclear export of microRNA precursors. Science. 2004;303(5654):95-8.

42. Bernstein E, Caudy AA, Hammond SM, Hannon GJ. Role for a bidentate ribonuclease in the initiation step of RNA interference. Nature. 2001; 409(6818):363.

43. Grishok A, Pasquinelli AE, Conte D, Li N, Parrish S, Ha I, et al. Genes and mechanisms related to RNA interference regulate expression of the small temporal RNAs that control C. elegans developmental timing. Cell. 2001; 106(1):23-34.

44. Hutvágner G, McLachlan J, Pasquinelli AE, Bálint É, Tuschl T, Zamore PD. A cellular function for the RNA-interference enzyme dicer in the maturation of the let-7 small temporal RNA. Science. 2001;293(5531):834-8.

45. Knight SW, Bass BL. A role for the RNase III enzyme DCR-1 in RNA interference and germ line development in Caenorhabditis elegans. Science. 2001;293(5538):2269-71.

46. Lee YS, Nakahara K, Pham JW, Kim K, He Z, Sontheimer EJ, et al. Distinct roles for Drosophila Dicer-1 and Dicer-2 in the siRNA/miRNA silencing pathways. Cell. 2004;117(1):69-81.

47. Liu J, Carmell MA, Rivas FV, Marsden CG, Thomson JM, Song J-J, et al. Argonaute2 is the catalytic engine of mammalian RNAi. Science. 2004; 305(5689):1437-41.

48. Fabian MR, Sonenberg N. The mechanics of miRNA-mediated gene silencing: a look under the hood of miRISC. Nat Struct Mol Biol. 2012;19(6):586.

49. Kurihara $Y$, Watanabe $Y$. Arabidopsis micro-RNA biogenesis through dicerlike 1 protein functions. Proc Natl Acad Sci U S A. 2004;101(34):12753-8.

50. Voinnet O. Origin, biogenesis, and activity of plant microRNAs. Cell. 2009; 136(4):669-87

51. Park MY, Wu G, Gonzalez-Sulser A, Vaucheret H, Poethig RS. Nuclear processing and export of microRNAs in Arabidopsis. Proc Natl Acad Sci U S A. 2005; 102(10):3691-6.

52. Fang $Y$, Spector DL. Identification of nuclear dicing bodies containing proteins for microRNA biogenesis in living Arabidopsis plants. Curr Biol. 2007;17(9):818-23.

53. Song L, Han M-H, Lesicka J, Fedoroff N. Arabidopsis primary microRNA processing proteins HYL1 and DCL1 define a nuclear body distinct from the Cajal body. Proc Natl Acad Sci U S A. 2007;104(13):5437-42.

54. Li J, Yang Z, Yu B, Liu J, Chen X. Methylation protects miRNAs and siRNAs from a 3'-end uridylation activity in Arabidopsis. Curr Biol. 2005; 15(16):1501-7. 
55. Baumberger N, Baulcombe D. Arabidopsis ARGONAUTE1 is an RNA slicer that selectively recruits microRNAs and short interfering RNAs. Proc Natl Acad Sci U S A. 2005;102(33):11928-33.

56. Qi Y, Denli AM, Hannon GJ. Biochemical specialization within Arabidopsis RNA silencing pathways. Mol Cell. 2005;19(3):421-8.

57. Vaucheret $\mathrm{H}$. Post-transcriptional small RNA pathways in plants: mechanisms and regulations. Genes Dev. 2006;20(7):759-71.

58. Lewis BP, Burge CB, Bartel DP. Conserved seed pairing, often flanked by adenosines, indicates that thousands of human genes are microRNA targets. Cell. 2005;120(1):15-20.

59. Selbach M, Schwanhäusser B, Thierfelder N, Fang Z, Khanin R, Rajewsky N. Widespread changes in protein synthesis induced by microRNAs. Nature. 2008;455(7209):58.

60. Grimson A, Farh KK-H, Johnston WK, Garrett-Engele P, Lim LP, Bartel DP. MicroRNA targeting specificity in mammals: determinants beyond seed pairing. Mol Cell. 2007;27(1):91-105.

61. Baek D, Villén J, Shin C, Camargo FD, Gygi SP, Bartel DP. The impact of microRNAs on protein output. Nature. 2008;455(7209):64.

62. Anderson EM, Birmingham A, Baskerville S, Reynolds A, Maksimova E, Leake $D$, et al. Experimental validation of the importance of seed complement frequency to siRNA specificity. RNA. 2008;14(5):853-61.

63. Lim LP, Lau NC, Garrett-Engele P, Grimson A, Schelter JM, Castle J, et al. Microarray analysis shows that some microRNAs downregulate large numbers of target mRNAs. Nature. 2005;433(7027):769.

64. Long $D$, Lee $R$, Williams $P$, Chan $C Y$, Ambros V, Ding Y. Potent effect of target structure on microRNA function. Nat Struct Mol Biol. 2007; 14(4):287.

65. Brodersen $\mathrm{P}$, Voinnet $\mathrm{O}$. Revisiting the principles of microRNA target recognition and mode of action. Nat Rev Mol Cell Biol. 2009;10(2):141.

66. Lal A, Navarro F, Maher CA, Maliszewski LE, Yan N, O'Day E, et al. miR-24 inhibits cell proliferation by targeting E2F2, MYC, and other cell-cycle genes via binding to "seedless" 3' UTR microRNA recognition elements. Mol Cell. 2009;35(5):610-25.

67. Lu L-F, Boldin MP, Chaudhry A, Lin L-L, Taganov KD, Hanada T, et al. Function of miR-146a in controlling Treg cell-mediated regulation of Th1 responses. Cell. 2010;142(6):914-29.

68. Loeb GB, Khan AA, Canner D, Hiatt JB, Shendure J, Darnell RB, et al. Transcriptome-wide miR-155 binding map reveals widespread noncanonical microRNA targeting. Mol Cell. 2012;48(5):760-70.

69. Tay Y, Zhang J, Thomson AM, Lim B, Rigoutsos I. MicroRNAs to Nanog, Oct4 and Sox 2 coding regions modulate embryonic stem cell differentiation. Nature. 2008:455(7216):1124.

70. Didiano D, Hobert O. Perfect seed pairing is not a generally reliable predictor for miRNA-target interactions. Nat Struct Mol Biol. 2006;13(9):849.

71. Seok H, Ham J, Jang E-S, Chi SW. MicroRNA target recognition: insights from transcriptome-wide non-canonical interactions. Mol Cells. 2016;39(5):375.

72. Kim D, Sung YM, Park J, Kim S, Kim J, Park J, et al. General rules for functional microRNA targeting. Nat Genet. 2016;48(12):1517.

73. Chi SW, Hannon GJ, Darnell RB. An alternative mode of microRNA target recognition. Nat Struct Mol Biol. 2012;19(3):321.

74. Shin C, Nam J-W, Farh KK-H, Chiang HR, Shkumatava A, Bartel DP. Expanding the microRNA targeting code: functional sites with centered pairing. Mol Cell. 2010;38(6):789-802.

75. Grosswendt S, Filipchyk A, Manzano M, Klironomos F, Schilling M, Herzog M, et al. Unambiguous identification of miRNA: target site interactions by different types of ligation reactions. Mol Cell. 2014;54(6):1042-54.

76. Helwak A, Kudla G, Dudnakova T, Tollervey D. Mapping the human miRNA interactome by CLASH reveals frequent noncanonical binding. Cell. 2013; 153(3):654-65

77. Moore MJ, Scheel TK, Luna JM, Park CY, Fak JJ, Nishiuchi E, et al. miRNAtarget chimeras reveal miRNA $3^{\prime}$-end pairing as a major determinant of Argonaute target specificity. Nat Commun. 2015;6:8864

78. Brodersen P, Sakvarelidze-Achard L, Bruun-Rasmussen M, Dunoyer P, Yamamoto YY, Sieburth L, et al. Widespread translational inhibition by plant miRNAs and siRNAs. Science. 2008:320(5880):1185-90.

79. Wang F, Polydore S, Axtell MJ. More than meets the eye? Factors that affect target selection by plant miRNAs and heterochromatic siRNAs. Curr Opin Plant Biol. 2015;27:118-24.

80. Jones-Rhoades MW, Bartel DP. Computational identification of plant microRNAs and their targets, including a stress-induced miRNA. Mol Cell. 2004;14(6):787-99.
81. Brousse C, Liu Q, Beauclair L, Deremetz A, Axtell MJ, Bouché N. A noncanonical plant microRNA target site. Nucleic Acids Res. 2014;42(8):5270-9.

82. Li F, Zheng Q, Vandivier LE, Willmann MR, Chen Y, Gregory BD. Regulatory impact of RNA secondary structure across the Arabidopsis transcriptome. Plant Cell. 2012;24(11):4346-59.

83. Kedde M, Strasser MJ, Boldajipour B, Vrielink JAO, Slanchev K, le Sage C, et al. RNA-binding protein Dnd1 inhibits microRNA access to target mRNA. Cell. 2007;131(7):1273-86.

84. Li J, Reichel M, Millar AA. Determinants beyond both complementarity and cleavage govern microR159 efficacy in Arabidopsis. PLoS Genet. 2014;10(3): e1004232.

85. Lytle JR, Yario TA, Steitz JA. Target mRNAs are repressed as efficiently by microRNA-binding sites in the $5^{\prime}$ UTR as in the 3' UTR. Proc Natl Acad Sci U S A. 2007;104(23):9667-72.

86. Schnall-Levin $\mathrm{M}$, Zhao $\mathrm{Y}$, Perrimon $\mathrm{N}$, Berger B. Conserved microRNA targeting in Drosophila is as widespread in coding regions as in 3' UTRs. Proc Natl Acad Sci U S A. 2010;107(36):15751-6.

87. Ameres SL, Horwich MD, Hung J-H, Xu J, Ghildiyal M, Weng Z, et al. Target RNA-directed trimming and tailing of small silencing RNAs. Science. 2010; 328(5985):1534-9.

88. Baccarini A, Chauhan H, Gardner TJ, Jayaprakash AD, Sachidanandam R, Brown BD. Kinetic analysis reveals the fate of a microRNA following target regulation in mammalian cells. Curr Biol. 2011;21(5):369-76.

89. Xie J, Ameres SL, Friedline R, Hung J-H, Zhang Y, Xie Q, et al. Long-term, efficient inhibition of microRNA function in mice using rAAV vectors. Nat Methods. 2012;9(4):403.

90. Sanei M, Chen X. Mechanisms of microRNA turnover. Curr Opin Plant Biol. 2015;27:199-206.

91. Ji L, Chen X. Regulation of small RNA stability: methylation and beyond. Cell Res. 2012;22(4):624.

92. Rüegger $\mathrm{S}$, Großhans H. MicroRNA turnover: when, how, and why. Trends Biochem Sci. 2012;37(10):436-46.

93. Bail S, Swerdel M, Liu H, Jiao X, Goff LA, Hart RP, et al. Differential regulation of microRNA stability. RNA. 2010;16(5):1032-9.

94. Diederichs $\mathrm{S}$, Haber DA. Dual role for argonautes in microRNA processing and posttranscriptional regulation of microRNA expression. Cell. 2007;131(6):1097-108.

95. Kawamata T, Tomari Y. Making risc. Trends Biochem Sci. 2010;35(7):368-76.

96. Ameres SL, Zamore PD. Diversifying microRNA sequence and function. Nat Rev Mol Cell Biol. 2013;14(8):475.

97. Wilson RC, Doudna JA. Molecular mechanisms of RNA interference. Annu Rev Biophys. 2013;42:217-39.

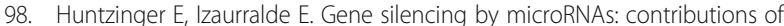
translational repression and mRNA decay. Nat Rev Genet. 2011;12(2):99.

99. Olsen $\mathrm{PH}$, Ambros $\mathrm{V}$. The lin-4 regulatory RNA controls developmental timing in Caenorhabditis elegans by blocking LIN-14 protein synthesis after the initiation of translation. Dev Biol. 1999;216(2):671-80.

100. Bagga S, Bracht J, Hunter S, Massirer K, Holtz J, Eachus R, et al. Regulation by let-7 and lin-4 miRNAs results in target mRNA degradation. Cell. 2005; 122(4):553-63.

101. Chekulaeva M, Mathys H, Zipprich JT, Attig J, Colic M, Parker R, et al. miRNA repression involves GW182-mediated recruitment of CCR4-NOT through conserved W-containing motifs. Nat Struct Mol Biol. 2011;18(11):1218.

102. Moretti F, Kaiser C, Zdanowicz-Specht A, Hentze MW. PABP and the poly (a) tail augment microRNA repression by facilitated miRISC binding. Nat Struct Mol Biol. 2012;19(6):603.

103. Jonas $S$, Izaurralde $E$. The role of disordered protein regions in the assembly of decapping complexes and RNP granules. Genes Dev. 2013;27(24):2628-41.

104. H-o I, Tomari Y. Molecular insights into microRNA-mediated translational repression in plants. Mol Cell. 2013;52(4):591-601.

105. Bologna NG, Voinnet O. The diversity, biogenesis, and activities of endogenous silencing small RNAs in Arabidopsis. Annu Rev Plant Biol. 2014; 65:473-503.

106. Carbonell A, Fahlgren N, Garcia-Ruiz H, Gilbert KB, Montgomery TA, Nguyen $T$, et al. Functional analysis of three Arabidopsis ARGONAUTES using slicerdefective mutants. Plant Cell. 2012;24(9):3613-29.

107. Qi Y, He X, Wang X-J, Kohany O, Jurka J, Hannon GJ. Distinct catalytic and non-catalytic roles of ARGONAUTE4 in RNA-directed DNA methylation. Nature. 2006:443(7114):1008

108. Takeda A, Iwasaki S, Watanabe T, Utsumi M, Watanabe Y. The mechanism selecting the guide strand from small RNA duplexes is different among argonaute proteins. Plant Cell Physiol. 2008;49(4):493-500. 
109. Zhu H, Hu F, Wang R, Zhou X, Sze S-H, Liou LW, et al. Arabidopsis Argonaute10 specifically sequesters miR166/165 to regulate shoot apical meristem development. Cell. 2011;145(2):242-56.

110. Souret FF, Kastenmayer JP, Green PJ. AtXRN4 degrades mRNA in Arabidopsis and its substrates include selected miRNA targets. Mol Cell. 2004;15(2):173-83.

111. Yu Y, Jia T, Chen X. The 'how' and 'where' of plant microRNAs. New Phytol. 2017;216(4):1002-17.

112. Ren G, Xie M, Zhang S, Vinovskis C, Chen X, Yu B. Methylation protects microRNAs from an AGO1-associated activity that uridylates 5' RNA fragments generated by AGO1 cleavage. Proc Natl Acad Sci U S A. 2014; 111(17):6365-70.

113. Ricci EP, Limousin T, Soto-Rifo R, Rubilar PS, Decimo D, Ohlmann T. miRNA repression of translation in vitro takes place during 435 ribosomal scanning. Nucleic Acids Res. 2012;41(1):586-98.

114. Jonas S, Izaurralde E. Towards a molecular understanding of microRNAmediated gene silencing. Nat Rev Genet. 2015;16(7):421.

115. Zekri L, Kuzuoğlu-Öztürk D, Izaurralde E. GW182 proteins cause PABP dissociation from silenced miRNA targets in the absence of deadenylation. EMBO J. 2013;32(7):1052-65.

116. Chen Y, Boland A, Kuzuoğlu-Öztürk D, Bawankar P, Loh B, Chang C-T, et al. A DDX6-CNOT1 complex and W-binding pockets in CNOT9 reveal direct links between miRNA target recognition and silencing. Mol Cell. 2014;54(5): 737-50.

117. Rouya C, Siddiqui N, Morita M, Duchaine TF, Fabian MR, Sonenberg N Human DDX6 effects miRNA-mediated gene silencing via direct binding to CNOT1. RNA. 2014;20(9):1398-409.

118. Nishimura T, Padamsi Z, Fakim H, Milette S, Dunham WH, Gingras A-C, et al. The elF4E-binding protein $4 \mathrm{E}-\mathrm{T}$ is a component of the mRNA decay machinery that bridges the $5^{\prime}$ and $3^{\prime}$ termini of target mRNAs. Cell Rep. 2015;11(9):1425-36.

119. Waghray S, Williams C, Coon JJ, Wickens M. Xenopus CAF1 requires NOT1mediated interaction with 4E-T to repress translation in vivo. RNA. 2015; 21(7):1335-45.

120. Meijer H, Kong Y, Lu W, Wilczynska A, Spriggs R, Robinson S, et al. Translational repression and elF4A2 activity are critical for microRNAmediated gene regulation. Science. 2013;340(6128):82-5.

121. Fukaya T, H-o I, Tomari Y. MicroRNAs block assembly of elF4F translation initiation complex in Drosophila. Mol Cell. 2014;56(1):67-78.

122. Fukao A, Mishima Y, Takizawa N, Oka S, Imataka H, Pelletier J, et al. MicroRNAs trigger dissociation of elF4AI and elF4All from target mRNAs in humans. Mol Cell. 2014;56(1):79-89.

123. Huntzinger E, Kuzuoğlu-Öztürk D, Braun JE, Eulalio A, Wohlbold L, Izaurralde E. The interactions of GW182 proteins with PABP and deadenylases are required for both translational repression and degradation of miRNA targets. Nucleic Acids Res. 2012;41(2):978-94.

124. Zekri L, Huntzinger $E$, Heimstädt S, Izaurralde $E$. The silencing domain of GW182 interacts with PABPC1 to promote translational repression and degradation of microRNA targets and is required for target release. Mol Cell Biol. 2009;29(23):6220-31.

125. Presnyak V, Coller J. The DHH1/RCKp54 family of helicases: an ancient family of proteins that promote translational silencing. BBA-Gene Regul Mech. 2013;1829(8):817-23.

126. Su H, Meng S, Lu Y, Trombly MI, Chen J, Lin C, et al. Mammalian hyperplastic discs homolog EDD regulates miRNA-mediated gene silencing. Mol Cell. 2011;43(1):97-109.

127. Chen X. A microRNA as a translational repressor of APETALA2 in Arabidopsis flower development. Science. 2004;303(5666):2022-5.

128. Gandikota M, Birkenbihl RP, Höhmann S, Cardon GH, Saedler H, Huijser P. The miRNA156/157 recognition element in the $3^{\prime}$ UTR of the Arabidopsis SBP box gene SPL3 prevents early flowering by translational inhibition in seedlings. Plant J. 2007:49(4):683-93.

129. Todesco M, Rubio-Somoza I, Paz-Ares J, Weigel D. A collection of target mimics for comprehensive analysis of microRNA function in Arabidopsis thaliana. PLoS Genet. 2010;6(7):e1001031.

130. Alonso-Peral MM, Li J, Li Y, Allen RS, Schnippenkoetter W, Ohms S, et al. The MicroRNA159-regulated GAMYB-like genes inhibit growth and promote programmed cell death in Arabidopsis. Plant Physiol. 2010;154(2):757-71.

131. Li S, Liu L, Zhuang $X, Y$, Y, Liu X, Cui X, et al. MicroRNAs inhibit the translation of target mRNAs on the endoplasmic reticulum in Arabidopsis. Cell. 2013;153(3):562-74.
132. Yang L, Wu G, Poethig RS. Mutations in the GW-repeat protein SUO reveal a developmental function for microRNA-mediated translational repression in Arabidopsis. Proc Natl Acad Sci U S A. 2012;109(1):315-20.

133. Fire A, Xu S, Montgomery MK, Kostas SA, Driver SE, Mello CC. Potent and specific genetic interference by double-stranded RNA in Caenorhabditis elegans. Nature. 1998;391(6669):806

134. Araujo R, Santos A, Pinto F, Gontijo N, Lehane M, Pereira M. RNA interference of the salivary gland nitrophorin 2 in the triatomine bug Rhodnius prolixus (Hemiptera: Reduviidae) by dsRNA ingestion or injection. Insect Biochem Mol Biol. 2006;36(9):683-93.

135. Turner C, Davy M, MacDiarmid R, Plummer K, Birch N, Newcomb R. RNA interference in the light brown apple moth, Epiphyas postvittana (Walker) induced by double-stranded RNA feeding. Insect Mol Biol. 2006;15(3):38391

136. Baum JA, Bogaert T, Clinton W, Heck GR, Feldmann P, llagan O, et al. Control of coleopteran insect pests through RNA interference. Nat Biotechnol. 2007;25(11):1322

137. Tian H, Peng H, Yao Q, Chen H, Xie Q, Tang B, et al. Developmental control of a lepidopteran pest Spodoptera exigua by ingestion of bacteria expressing dsRNA of a non-midgut gene. PLoS One. 2009;4(7):e6225.

138. Chen X, Ba Y, Ma L, Cai X, Yin Y, Wang K, et al. Characterization of microRNAs in serum: a novel class of biomarkers for diagnosis of cancer and other diseases. Cell Res. 2008;18(10):997.

139. Chim SS, Shing TK, Hung EC, T-y L, T-k L, Chiu RW, et al. Detection and characterization of placental microRNAs in maternal plasma. Clin Chem 2008:54(3):482-90.

140. Lawrie CH, Gal S, Dunlop HM, Pushkaran B, Liggins AP, Pulford K, et al. Detection of elevated levels of tumour-associated microRNAs in serum of patients with diffuse large B-cell lymphoma. Br J Haematol. 2008;141(5):672-

141. Mitchell PS, Parkin RK, Kroh EM, Fritz BR, Wyman SK, Pogosova-Agadjanyan EL, et al. Circulating microRNAs as stable blood-based markers for cancer detection. Proc Natl Acad Sci U S A. 2008;105(30):10513-8.

142. Liang G, Zhu Y, Sun B, Shao Y, Jing A, Wang J, et al. Assessing the survival of exogenous plant microRNA in mice. Food Sci Nutr. 2014;2(4):380-8.

143. Liang $H$, Zhang S, Fu Z, Wang $Y$, Wang N, Liu Y, et al. Effective detection and quantification of dietetically absorbed plant microRNAs in human plasma. J Nutr Biochem. 2015;26(5):505-12.

144. Yang J, Farmer LM, Agyekum AA, Hirschi KD. Detection of dietary plantbased small RNAs in animals. Cell Res. 2015;25(4):517.

145. Yang J, Farmer LM, Agyekum AA, Elbaz-Younes I, Hirschi KD. Detection of an abundant plant-based small RNA in healthy consumers. PLoS One. 2015; 10(9):e0137516.

146. Yang J, Hotz T, Broadnax L, Yarmarkovich M, Elbaz-Younes I, Hirschi KD. Anomalous uptake and circulatory characteristics of the plant-based small RNA MIR2911. Sci Rep. 2016;6:26834.

147. Yang J, Kongchan N, Primo Planta C, Neilson JR, Hirschi KD. The atypical genesis and bioavailability of the plant-based small RNA MIR2911: bulking up while breaking down. Mol Nutr Food Res. 2017;61(9):1600974.

148. Palíková I, Heinrich J, Bednář P, Marhol P, Vr K, Cvak L, et al. Constituents and antimicrobial properties of blue honeysuckle: a novel source for phenolic antioxidants. J Agric Food Chem. 2008;56(24):11883-9.

149. Philip A, Ferro VA, Tate RJ. Determination of the potential bioavailability of plant microRNAs using a simulated human digestion process. Mol Nutr Food Res. 2015:59(10):1962-72.

150. Mlotshwa S, Pruss GJ, MacArthur JL, Endres MW, Davis C, Hofseth LJ, et al. A novel chemopreventive strategy based on therapeutic microRNAs produced in plants. Cell Res. 2015;25(4):521.

151. Chin AR, Fong MY, Somlo G, Wu J, Swiderski P, Wu X, et al. Cross-kingdom inhibition of breast cancer growth by plant miR159. Cell Res. 2016;26(2):217.

152. Cavalieri D, Rizzetto L, Tocci N, Rivero D, Asquini E, Si-Ammour A, et al. Plant microRNAs as novel immunomodulatory agents. Sci Rep. 2016;6:25761.

153. Wang W, Hang C, Zhang Y, Chen M, Meng X, Cao Q, et al. Dietary miR-451 protects erythroid cells from oxidative stress via increasing the activity of Foxo3 pathway. Oncotarget. 2017:8(63):107109.

154. Dickinson B, Zhang Y, Petrick JS, Heck G, Ivashuta S, Marshall WS. Lack of detectable oral bioavailability of plant microRNAs after feeding in mice. Nat Biotechnol. 2013;31(11):965.

155. Zhang Y, Wiggins BE, Lawrence C, Petrick J, Ivashuta S, Heck G. Analysis of plant-derived miRNAs in animal small RNA datasets. BMC Genomics. 2012; 13(1):381 
156. Tosar JP, Rovira C, Naya H, Cayota A. Mining of public sequencing databases supports a non-dietary origin for putative foreign miRNAs: underestimated effects of contamination in NGS. RNA. 2014;20(6):754-7.

157. Baier SR, Nguyen C, Xie F, Wood JR, Zempleni J. MicroRNAs are absorbed in biologically meaningful amounts from nutritionally relevant doses of cow Milk and affect gene expression in peripheral blood mononuclear cells, HEK-293 kidney cell cultures, and mouse livers-3. J Nutr. 2014;144(10):1495-500.

158. Snow JW, Hale AE, Isaacs SK, Baggish AL, Chan SY. Ineffective delivery of diet-derived microRNAs to recipient animal organisms. RNA Biol. 2013;10(7): 1107-16.

159. Witwer KW, McAlexander MA, Queen SE, Adams RJ. Real-time quantitative PCR and droplet digital PCR for plant miRNAs in mammalian blood provide little evidence for general uptake of dietary miRNAs: limited evidence for general uptake of dietary plant xenomiRs. RNA Biol. 2013;10(7):1080-6.

160. Huang $H$, Davis CD, Wang TT. Extensive degradation and low bioavailability of orally consumed corn miRNAs in mice. Nutrients. 2018;10(2):215.

161. Chen X, Liang H, Zhang J, Zen K, Zhang C-Y. Secreted microRNAs: a new form of intercellular communication. Trends Cell Biol. 2012;22(3):125-32.

162. Mathivanan S, Ji H, Simpson RJ. Exosomes: extracellular organelles important in intercellular communication. J Proteome. 2010;73(10):1907-20.

163. van der Pol E, Böing AN, Harrison P, Sturk A, Nieuwland R. Classification, functions, and clinical relevance of extracellular vesicles. Pharmacol Rev. 2012;64(3):676-705.

164. Keller S, Ridinger J, Rupp A-K, Janssen JW, Altevogt P. Body fluid derived exosomes as a novel template for clinical diagnostics. J Transl Med. 2011;9(1):86

165. Cheng L, Sharples RA, Scicluna BJ, Hill AF. Exosomes provide a protective and enriched source of miRNA for biomarker profiling compared to intracellular and cell-free blood. J Extracell Vesicles. 2014;3(1):23743.

166. Mu J, Zhuang X, Wang Q, Jiang H, Deng ZB, Wang B, et al. Interspecies communication between plant and mouse gut host cells through edible plant derived exosome-like nanoparticles. Mol Nutr Food Res. 2014:58(7):1561-73.

167. Wang K, Zhang S, Weber J, Baxter D, Galas DJ. Export of microRNAs and microRNA-protective protein by mammalian cells. Nucleic Acids Res. 2010; 38(20):7248-59.

168. Vickers KC, Palmisano BT, Shoucri BM, Shamburek RD, Remaley AT. MicroRNAs are transported in plasma and delivered to recipient cells by high-density lipoproteins. Nat Cell Biol. 2011;13(4):423.

169. Beltrami C, Clayton A, Newbury LJ, Corish P, Jenkins RH, Phillips AO, et al. Stabilization of urinary microRNAs by association with exosomes and argonaute 2 protein. Non-Coding RNA. 2015;1(2):151-66.

170. Luo Y, Wang P, Wang X, Wang Y, Mu Z, Li Q, et al. Detection of dietetically absorbed maize-derived microRNAs in pigs. Sci Rep. 2017;7(1):645.

171. Saleh M-C, van Rij RP, Hekele A, Gillis A, Foley E, O'Farrell PH, et al. The endocytic pathway mediates cell entry of dsRNA to induce RNAi silencing Nat Cell Biol. 2006;8(8):793

172. Winston WM, Sutherlin M, Wright AJ, Feinberg EH, Hunter CP. Caenorhabditis elegans SID-2 is required for environmental RNA interference. Proc Natl Acad Sci U S A. 2007;104(25):10565-70.

173. Duxbury MS, Ashley SW, Whang EE. RNA interference: a mammalian SID-1 homologue enhances siRNA uptake and gene silencing efficacy in human cells. Biochem Biophys Res Commun. 2005;331(2):459-63.

174. Elhassan MO, Christie J, Duxbury MS. Homo sapiens systemic RNA interference-defective-1 transmembrane family member 1 (SIDT1) protein mediates contact-dependent small RNA transfer and microRNA-21-driven chemoresistance. J Biol Chem. 2012;287(8):5267-77.

175. Peterson LW, Artis D. Intestinal epithelial cells: regulators of barrier function and immune homeostasis. Nat Rev Immunol. 2014;14(3):141.

176. Witwer KW, Hirschi KD. Transfer and functional consequences of dietary microRNAs in vertebrates: concepts in search of corroboration: negative results challenge the hypothesis that dietary xenomiRs cross the gut and regulate genes in ingesting vertebrates, but important questions persist. BioEssays. 2014;36(4):394-406.

177. Shah MY, Calin GA. The mix of two worlds: non-coding RNAs and hormones. Nucleic Acid Ther. 2013;23(1):2-8.

178. Bayraktar R, Van Roosbroeck K, Calin GA. Cell-to-cell communication: microRNAs as hormones. Mol Oncol. 2017;11(12):1673-86.

179. Skog J, Würdinger T, Van Rijn S, Meijer DH, Gainche L, Curry WT Jr, et al. Glioblastoma microvesicles transport RNA and proteins that promote tumour growth and provide diagnostic biomarkers. Nat Cell Biol. 2008; 10(12):1470
180. Mittelbrunn M, Gutiérrez-Vázquez C, Villarroya-Beltri C, González S, SánchezCabo F, González MÁ, et al. Unidirectional transfer of microRNA-loaded exosomes from T cells to antigen-presenting cells. Nat Commun. 2011;2:282

181. Dai A, Sun H, Fang T, Zhang Q, Wu S, Jiang Y, et al. MicroRNA-133b stimulates ovarian estradiol synthesis by targeting Foxl2. FEBS Lett. 2013; 587(15):2474-82.

182. Wu S, Sun H, Zhang Q, Jiang Y, Fang T, Cui I, et al. MicroRNA-132 promotes estradiol synthesis in ovarian granulosa cells via translational repression of Nurr1. Reprod Biol Endocrinol. 2015;13(1):94.

183. Gai Y, Zhang J, Wei C, Cao W, Cui Y, Cui S. miR-375 negatively regulates the synthesis and secretion of catecholamines by targeting Sp1 in rat adrenal medulla. Am J Physiol Cell Physiol. 2017;312(5):C663-C72.

184. Romero DG, Plonczynski MW, Carvajal CA, Gomez-Sanchez EP, GomezSanchez CE. Microribonucleic acid-21 increases aldosterone secretion and proliferation in H295R human adrenocortical cells. Endocrinology. 2008; 149(5):2477-83.

185. Hu Z, Shen W-J, Cortez Y, Tang X, Liu L-F, Kraemer FB, et al. Hormonal regulation of microRNA expression in steroid producing cells of the ovary, testis and adrenal gland. PLoS One. 2013;8(10):e78040.

186. Dong H, Paquette M, Williams A, Zoeller RT, Wade M, Yauk C. Thyroid hormone may regulate mRNA abundance in liver by acting on microRNAs. PLoS One. 2010:5(8):e12136.

187. Yap CS, Sinha RA, Ota S, Katsuki M, Yen PM. Thyroid hormone negatively regulates CDX2 and SOAT2 mRNA expression via induction of miRNA-181d in hepatic cells. Biochem Biophys Res Commun. 2013;440(4):635-9.

188. Zhang N, J-k L, Chen J, X-f L, J-I L, H-s L, et al. MicroRNA 375 mediates the signaling pathway of corticotropin-releasing factor (CRF) regulating proopiomelanocortin (POMC) expression by targeting mitogen-activated protein kinase 8. J Biol Chem. 2013;288(15):10361-73.

189. Choi JW, Kang SM, Lee Y, Hong SH, Sanek NA, Young WS, et al. MicroRNA profiling in the mouse hypothalamus reveals oxytocin-regulating microRNA. J Neurochem. 2013;126(3):331-7.

190. Ye R-S, Xi Q-Y, Qi Q, Cheng X, Chen T, Li H, et al. Differentially expressed miRNAs after $\mathrm{GnRH}$ treatment and their potential roles in FSH regulation in porcine anterior pituitary cell. PLoS One. 2013:8(2):e57156.

191. Reyes JL, Chua NH. ABA induction of miR159 controls transcript levels of two MYB factors during Arabidopsis seed germination. Plant J. 2007:49(4): 592-606.

192. Fan LM, Feng X, Wang Y, Deng XW. Gibberellin signal transduction in rice. J Integr Plant Biol. 2007;49(6):731-41.

193. Achard P, Herr A, Baulcombe DC, Harberd NP. Modulation of floral development by a gibberellin-regulated microRNA. Development. 2004; 131(14):3357-65.

194. Boualem A, Laporte $P$, Jovanovic M, Laffont C, Plet J, Combier JP, et al. MicroRNA166 controls root and nodule development in Medicago truncatula. Plant J. 2008;54(5):876-87.

195. Liu Q, Zhang Y-C, Wang C-Y, Luo Y-C, Huang Q-J, Chen S-Y, et al. Expression analysis of phytohormone-regulated microRNAs in rice, implying their regulation roles in plant hormone signaling. FEBS Lett. 2009;583(4):723-8.

196. Subramanian S, Fu Y, Sunkar R, Barbazuk WB, Zhu J-K, Yu O. Novel and nodulation-regulated microRNAs in soybean roots. BMC Genomics. 2008; 9(1):160.

Ready to submit your research? Choose BMC and benefit from:

- fast, convenient online submission

- thorough peer review by experienced researchers in your field

- rapid publication on acceptance

- support for research data, including large and complex data types

- gold Open Access which fosters wider collaboration and increased citations

- maximum visibility for your research: over $100 \mathrm{M}$ website views per year

At $\mathrm{BMC}$, research is always in progress.

Learn more biomedcentral.com/submission 